\title{
Evaluating the Nature of Distractive Driving Factors towards Road Traffic Accident
}

\author{
Khawar Khan ${ }^{\text {a }}$, Syed Bilal Zaidi ${ }^{\text {a }}$, Asad Ali ${ }^{\text {a* }}$ \\ ${ }^{a}$ Department of Civil Engineering, University of Engineering and Technology, Taxila, 47050, Pakistan. \\ Received 04 May 2020; Accepted 23 July 2020
}

\begin{abstract}
For past two decades many researchers have been working on quantitative as well as qualitative study of distractive driving using different approaches. Road traffic accidents have been identified as the main source of human casualties and cause of damages to the economy and society, as millions of humans is killed every year in these accidents around the world. National-level studies in Pakistan reveal that a higher percentage of males in the age group from twenty to forty years lose their lives in road traffic accidents when compared with that of females. Due to these factors, it is alarming for a society, which is highly dependent on males such as Pakistan, as these losses put numerous families into the financial crisis that lead to poverty. This study envisaged identifying whether moods and emotions play any role in road traffic accidents of young drivers. The study reviews have shown various gaps in our understanding. For this purpose, qualitative interviews of young drivers who are university going and have met some road accidents in recent years in Pakistan had been conducted. Data from the interviews had been transcribed for analysis while maintaining the anonymity of the participants for confidentiality. Analysis of the transcribed data reveals various factors that contribute to road traffic accidents where major causes are distractions, different weather conditions, sleep deprivation, unsafe lane changes, night-time driving, and these factors are triggered by the behavior when youthful drivers engage in driving for sensation seeking and self-esteem. We conclude that it is just through the appropriation of a systems approach that coordinated countermeasures can be proposed and actualized to relieve driver mistakes caused by distraction.
\end{abstract}

Keywords: Drivers Mood; Sensation Seeking; Road Safety; Road Traffic Accident; Risky Driving.

\section{Introduction}

Road Traffic Accidents (RTAs) are documented as the core source of human and financial calamity [1,2] as it creates a global, social and economic issue, and millions of people are killed every year in these accidents [3]. Crashes of cars and injuries from road accidents are the leading reasons for death in the world, causing circa 1.35 million deaths every year. Traffic injuries are the major cause of death in people ranging from five to twenty-nine years [4]. In Pakistan, over 11,000 people died, and more than 15,000 injured in traffic accidents in 2017-18 [5]. It is alarming, especially for a society that depends on males like Pakistan since these losses drive numerous families into economic disaster leading to poverty. National-level studies in Pakistan disclose that a comparatively higher percentage of males in the age group from twenty to forty years lost their lives in RTA compared to females [6, 7]. Rapid motorization and development of infrastructure for road transport are expected to entice drivers further to engage in distinctive driving behaviors.

Road traffic accidents are the prevailing damage related reason for passing's, particularly in guys and all-inclusive positioned on ninth in the year 1999 [8]. As indicated by evaluation in the year 2002, 180,500 guys passed on due to

\footnotetext{
* Corresponding author: 2012civil20@student.uet.edu.pk
} 
RTAs, and 97\% of these RTAs expiries happened, particularly in developing nations around the world [4]. Different audits have shown the hostile atmosphere conditions on RTAs [9]. Security on the roads a general prosperity fragile issue; the results exhibit that more than 1.17 million individuals pass-on on yearly in RTAs around the globe. About more than 10 million are disabled or hurt every year [4]. Around 3000 people kick the container worldwide continually due to RTAs. The pace of RTAs is expanding a result of augmentation in-vehicle people. Road traffic accidents are declining in high-income countries yet increasing in developing countries [10, 11]. Accordingly, assessing the underlying drivers of RTAs both at a national and universal level is a significant worry for analysts and policymakers [12]. The amendment of this basic concern is the need for time as because sheltered voyaging is the foundation of a wide-open transportation framework, which is at last connected with the advancement of a country [13]. Financial improvement of any nation relies upon a safe street traffic framework and transportations of products. According to Ahmed [14], on-street security in a developing country like Pakistan has estimations that between 7000 , to10000 people lose their lives consistently in Pakistan.

Youngsters drive all the more recklessly and are associated with more car accidents than some other age gathering [15]. Vehicle crashes are a significant reason for the damage, incapacity, and demise among adolescents [16]. As men participate in crazy driving more than ladies, youthful guys are at the most serious hazard [17]. Considering the high number of youth among the drivers, a broad assortment of driving practices are routinely exhibited out and about, for example, respectful activities (e.g., enabling others to converge on the roadway), inadvertent mistakes (e.g., backing up and about hitting another vehicle), purposeful transgressions (e.g., running a red light), and reactions to the activities of different drivers (e.g., blaring horn in the wake of being cut off). Also, other parameters that show reckless driving include speed, headway, and frequent lane changes, especially in an abrupt manner. Driving practices differ essentially in the degree to which they may represent a danger to different drivers, and scientists use drivers' frequencies of taking part in various practices to make derivations about ordinary driving-related feelings and activities. Annoyance, anger, shock, threat, excitement, and frustration were the most common causes of aggressive driving [18]. Mesken, Hagenzieker [19] reported that happiness, anxiety, and anger were associated with RTAs. When negative emotions are considered, anger was mostly related to the events that hindered development [19]. Levelt [20] reported that negative emotions such as anger, fear, and grief one and half times less frequently than positive ones while driving. Also, the existing emotional state of an individual has the probability of lead him/her for aggressive behavior [21, 22]. Only a few research in the past studied multiple emotions [18, 19]. Some of the past studies have reported relation of driving to self-esteem and higher sensation seeking are related to a higher degree of risk-taking behavior during driving [23].

Some people, especially young, relate driving to self-esteem. Young drivers use their vehicles to augment their self-esteem, and irresponsible driving could seem to be beneficial [24]. Therefore, youthful drivers who identify driving relevant to self-esteem display a higher degree of willingness to take risks while driving [25]. Whereas, sensation-seeking is the propensity to have experiences, which are 'fluctuated, novel, unpredictable and extreme,' and the availability to go out to do as such, and reflects individual differences in ideal degree of excitement and stimulation [26]. It has been found that people with a high degree of sensation seeking have more potential to engage in more reckless driving and are involved with a higher number of RTA than those who score low in this personality attribute [27, 28].

Aggressive behaviors of driving are the most studied phenomenon through self-report data [29-31]. Some studies were done in recent years [32-34] endorse high risk driving behavior as the key factor that contributes to RTA [35]. Dangerous driving behavior related to RTAs comprises over speeding, driving when drunk, driving when exhausted, and driving without wearing seat belts [32]. An evaluation of some past studies brings into attention the role of affecting and emotional aspects in seeing and assessing risk [36-38]. Most of the past research on risky behavior while driving focused on risk perception, attitudes of individuals, emotions, and a few personality attributes. It has been observed that positive emotions relate to heightened sensitivity to loss and lead to an inclination to avoid risks [39]. Listening to pleasing music has also been found to make drivers drive fast and tempt to take risks [40, 41]. However, very little consideration has been given to find the effects of explicit positive emotions [42]. Often there are circumstances when one could hardly explain what precise emotion he/ she is feeling but simply describing as 'good' or 'bad' [43]. O'Brien [18] reported based on qualitative analysis that half of the participants felt it difficult to explain when speaking of what emotion they were feeling. Therefore, an investigation of specific risky behavior while driving may help explain risk-taking behavior and RTAs connection, thus contributing to the body of knowledge that could be used to improve road traffic safety. It will help to identify the behavior of the persons involved in RTAs in Pakistan.

Pakistan is one of the developing countries of the world and positioned as the sixth most crowded nation in the globe. The RTCs fatalities and inabilities in low- and middle-income nations are over $85 \%$ and $90 \%$, respectively [44]. In Pakistan, the walkers and the rider of mechanized ( 2 or 3 wheelers) at on more serious hazards and the main source of RTCs fatalities $41 \%$ and $39 \%$ respectively [4]. The generally evaluated cost identified with car accidents is $1 \%$, $1.5 \%$, and $2 \%$ of the Gross national items in the lower center and high pay nations, respectively [8]. For Pakistan, that cost is assessed to be $2 \%$ of Pakistan's GDP [45].The principle reason for traffic street mishap is the absence of 
mindfulness about traffic sense codes and requests, driver-related factors, over-burdening over speed utilization of mobile phones during driving, and vehicle-related factors[13]. A study based investigation in Islamabad, the capital of Pakistan, discovered the general inadequate about street security mindfulness, while the information taken from the medical clinic indicated that 87\% RTAs cases because of the carelessness of traffic law [46]. The poor implementation of transit regulations on seat-construct and protective cap-wearing in Pakistan [47]. The requirement of the new street laws assumes an essential job in the decrease of RTAs and mortality [48]. The effect of traffic street mishap is altogether connected with the person in question and their families and the national economy, especially for a developing one $[8,49]$.

Pakistan is a developing nation with a joint family framework, and a couple procuring part/s, for the most part, assumes a significant job in dealing with their families financially. That is the reason generally dynamic part/s of the families move outside from their homes, so they are increasingly inclined to wounds, handicaps, and even demise due to RTAs. In this way, such occasions become the general medical problem and financial misfortunes as far as harmed vehicles. Portability is the center of our opportunity. It is the rudimentary layer of our cutting edge and quick development. Thus, portability is a significant segment of the coordinated effort in our general public; in any case, it might likewise turn into our adversary where wellbeing measures are ignored. The general public pays an immense monetary misfortune regarding injuries, handicaps, and property misfortune from portability as a result of RTAs. It might look dubious about the feeling that RTAs are because of portability. However, it is valid. The development of the transportation framework has the power that activated human advancements to bloom on the earth. Be that as it may, this development additionally rose wellbeing and security issues because of extended transportation frameworks. In this way, a little separation ought to be secured by strolling as a person on foot travel offers a wide scope of advantages to the two people and society [50] and limited the odds of RTAs.

Earlier studies have examined the impact of positive affect on the desire to engage in reckless driving on the road were based on self-reported cross-sectional survey questionnaires. This study adopts a behavioral approach to explore the influence of the personal experience of mood, emotions (not essentially anger). The existing emotional state of an individual is likely to be the prime reason for a person to engage in aggressive behavior while driving.

\section{Literature Review}

\subsection{Literature Search}

Following samples were used during the experiments. In recent decades, a lot of exertion has been put resources into researching perilous driving and vehicle crashes among youthful drivers. Theories of behavior of drivers, what's more, adjustment recommend that drivers may work to keep up an satisfactory degree of hazard [54-57] or, on the other hand, task trouble [58-61] during the driving errand. For instance, Wilde [56] 'chance homeostasis hypothesis' sees society and individual drivers as endeavoring to keep up an objective degree of in general hazard, whereby if chance in one region is decreased, at that point chance-taking in the equivalent or another framework will increment. Summala's 'zero-chance model' of driver conduct [54] suggests that drivers endeavor to keep up a stable harmony among emotional and target hazard, wherein they abstain from feeling trepidation (and experience "zero-chance") when they drive by envisioning some level of hazard during the execution of the driving task. Summala's later 'various safe place model' of driver conduct [57] considers heading to be being constrained by the checking of different security edges, as opposed to 'chance' as the sole control work. Correspondingly, Vaa's 'hazard screen model' of driver conduct [55] proposes an assortment of target 'best sentiments' that drivers focus on, which incorporate sentiments of hazard. Fuller [59] Risk Allostasis Theory (RAT) of driver conduct, which draws on a prior Task Ability Interface (TCI) model, places that, by looking at them possess capacity to saw driving assignment trouble, drivers make constant, ongoing choices to keep up task trouble (or hazard) inside a favored range. A typical component of these models of driver conduct is that support of hazard, or errand trouble, is thought to happen through changes in vehicle parameters, including, for instance, speed. Rehashed thinks about have noticed that appraisals of saw task trouble relate with a driver's evaluations of sentiments of 'chance' [60, 61].

The primary instrument by which drivers are accepted to regulate task trouble (or hazard) inside their favored range is by expanding or diminishing their vehicle speed. There is sensible exploratory help for these suppositions. At the point when drivers communicate with in-vehicle innovations, for example, cell phones or theater setups, which increment generally driving errand trouble, decrease in vehicle speed is one of the most widely recognized changes in watched driver execution [62-64]. So also, when vehicle speed is held consistent by, for instance, Adaptive Cruise Control (ACC), drivers react to changes in task request by adjusting their conduct in different manners, for instance by giving less consideration to the street ahead and more regard for non-driving-related in-vehicle assignments [65, 66]. On account of the relationship among vehicle speed, street condition multifaceted nature and crash chance, and the focal job given to vehicle speed decision to keep up level of undertaking trouble, or hazard, during the driving assignment, RAT [59] and driving relevant to self-esteem [25] was picked as the hypothetical premise to control the present investigation's structure, including choice of variables. 
Youngsters drive all the more carelessly and are associated with more car accidents than some other age gathering [15]. Vehicle crashes are a significant reason for the damage, incapacity, and cause of death among youth [16]. As men take part in crazy driving more than ladies, youthful guys are at the most serious hazard [17]. A few aspects have been found to represent their driving style, including driving examples described by overexposure to hazardous circumstances; character characteristics, for example, sensation seeking [67], impulsivity [68], egocentricity [69], road aggression[70], and external locus of control [71]; enthusiastic state, with negative influence prompting heightened risk-taking [72]; inspiration, whereby wild driving furnishes youths with auxiliary advantages and addresses certain issues [73]; situational factors, for example, time weight and clog [74]; and social condition. Companions of the drivers figure unequivocally forming the conduct of youthful individuals through the setting of driving standards, impersonation, and friend pressure. In reality, the nearness of young people in the vehicle has been found to improve the probability of a car accident [75]. Other environmental factors that impact driving behavior and lead to RTAs are summarized here for the understanding of the readers of this study. The taxonomy furnished in Table 1, classifies numerous distraction resources for which something is understood about their crash hazard or contribution. It additionally incorporates the sorts of distraction (visible, cognitive, bodily) associated with each distraction source and facts regarding the chances of being involved in a crash or near-crash associated with each source and the percentage of distraction-associated crashes in which the source has been observed to be a contributing thing. Taken together the crash facts contained in table 2.1 suggests that distracting doings that require high ranges of visual-manual resources are associated with a notably better crash chance than the ones obligations that require largely cognitive means.

Table 1. Distractive driving, its sources, and their related crash risk and involvement to crashes

\begin{tabular}{|c|c|c|c|c|}
\hline $\begin{array}{c}\text { Category of Major } \\
\text { Source }\end{array}$ & Specific source & $\begin{array}{c}\text { Type of } \\
\text { distraction }\end{array}$ & $\begin{array}{c}\text { Crashing } \\
\text { Odds/near-crash }^{\mathrm{a}}\end{array}$ & $\begin{array}{l}\text { \% of distraction crashes } \\
\text { contributed by sources }\end{array}$ \\
\hline \multirow[t]{5}{*}{ Technology-based } & Talking on Mobile Phones & $\mathrm{C}, \mathrm{P}$ & $1.3-9.0$ & $2.1-8.8^{\mathrm{c}}$ \\
\hline & Dialling/Answering Mobile phones & $\mathrm{V}, \mathrm{P}$ & 2.8 & $0.0-8.8^{\mathrm{c}}$ \\
\hline & Radio, CD, Cassettes or MP3 Player & $\mathrm{C}, \mathrm{V}, \mathrm{P}$ & $0.6^{\mathrm{d}}-2.3^{\mathrm{e}}$ & $0 . .0-8.5$ \\
\hline & Text Messaging & $\mathrm{C}, \mathrm{V}, \mathrm{P}$ & 23.2 & \\
\hline & Other Devices (PDA, Blackberry) & $\mathrm{C}, \mathrm{V}, \mathrm{P}$ & & 0.0 \\
\hline \multirow[t]{12}{*}{ Non-Technology Based } & Moving Objects in vehicle & $\mathrm{V}, \mathrm{P}$ & $11.2^{\mathrm{f}}$ & 1.4 \\
\hline & Reading/writing & $\mathrm{C}, \mathrm{V}, \mathrm{P}$ & 7.4 & $2.1-6.9$ \\
\hline & Eating/drinking & $\mathrm{V}, \mathrm{P}$ & $1.0^{\mathrm{g}}-1.6^{\mathrm{h}}$ & $0.0-5.2$ \\
\hline & Personal grooming hygiene & $\mathrm{V}$ & $0.4-3.1$ & 0.0 \\
\hline & Vehicle/climate controls & $\mathrm{V}, \mathrm{P}$ & & $1.4-7.4$ \\
\hline & Vehicle mirrors and instrument panel & $\mathrm{V}, \mathrm{C}$ & & 1.4 \\
\hline & Smoking & $\mathrm{V}$ & & $0.0-3.8$ \\
\hline & Non-moving object in vehicle & $\mathrm{V}, \mathrm{P}$ & $1.4^{\mathrm{i}}$ & \\
\hline & Trying to find destination/location, lost & $\mathrm{V}, \mathrm{C}$ & & 5.9 \\
\hline & Reaching for objects & $\mathrm{V}, \mathrm{P}$ & & 2.8 \\
\hline & Sneezing/coughing/itching & $\mathrm{P}$ & & $<1.0$ \\
\hline & Daydreaming(lost in thoughts) & $\mathrm{C}$ & & $2.8-11.2$ \\
\hline \multirow[t]{5}{*}{ External-to-vehicle } & Outside event/object & $\mathrm{V}, \mathrm{C}$ & 3.7 & $0-9.7$ \\
\hline & Crash, roadside incident, other traffic & $\mathrm{V}, \mathrm{C}$ & & 3.8 \\
\hline & Scenery /landmarks & $\mathrm{V}, \mathrm{C}$ & & $1.7-2.9$ \\
\hline & Advertising/billboards & $\mathrm{V}, \mathrm{C}$ & & $<1.0$ \\
\hline & Pedestrian/cyclist & $\mathrm{V}, \mathrm{C}$ & & 0 \\
\hline Other/Unknown & & & & 10.4 \\
\hline
\end{tabular}




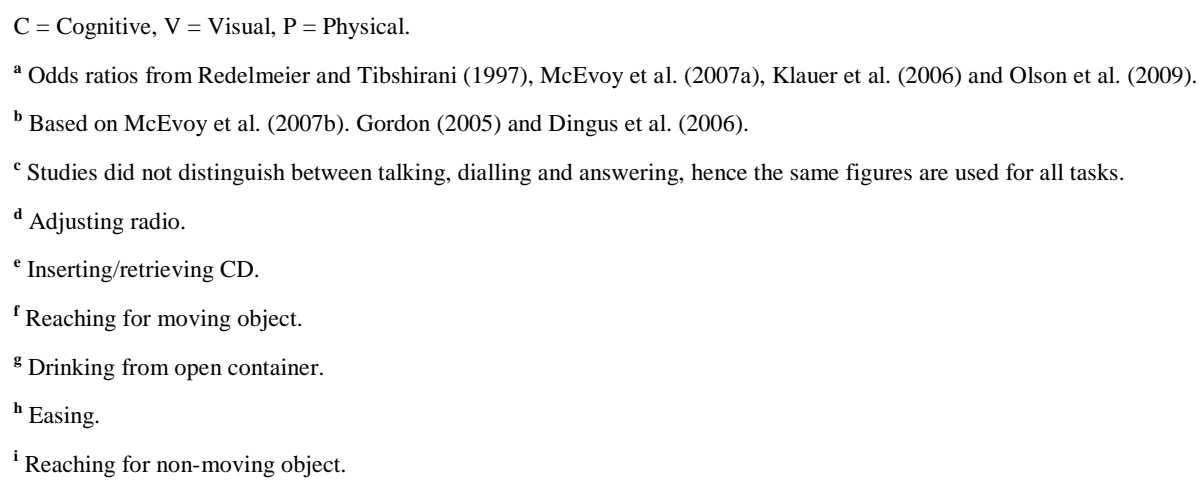

\subsection{Environmental Factors that Impact Road Traffic Accidents}

\subsubsection{Impact of Weather Conditions on Road Traffic Accidents}

A couple of researchers exhibit that most travelers do lean toward some particular kind of movement decision under these hostile atmospheric conditions [76, 77]. Weather conditions are consistently joined via pointer factors [78]. Saneinejad, Kennedy [79] explored the impacts of different atmospheric conditions on the transportation system using a disaggregate mode choice showcase and surveyed using travel activity data and looking at evident assorted atmosphere conditions. The investigation of Bergel-Hayat, Debbarh [80] likewise demonstrated the connection between these was weather conditions and street mishaps evaluated for the most part by and large premise. In financial terms, the expense of RTAs incapacitates, and wounds are assessed $1 \%$ of gross national thing (GNP) in low-salary nations like Pakistan, $1.5 \%$ in center pay, and $2 \%$ in high-wage countries [81]. The money related expenses of RTAs and wounds is reviewed to be over Rs100 billion for Pakistan (Ahmad 2006). In the developing countries, the masses packs displayed to the most bewildering perils of impairment, damage, and destruction from RTAs, individuals by walking, and customers on bicycles are from lower budgetary families [82, 83]. Recent reviews have exhibited that individuals by walking and motorcyclists have a highpace of harm in Asia [84, 85].

In Pakistan, the occurrence of road traffic injuries was 15 for every 1000 individuals consistently [82]. It is moreover seen that more youthful guys are hurt than the female of the same age gathering, and adolescents from more unfortunate families have higher paces of harm because of their open-air obligation. In 2002, $73 \%$ folks spoke to of all street traffic expiries, with around multiple times higher than that of females, i.e., 27.6 for every 100,000 masses and 10.4 for every 100,000 people separately [4]. It is overviewed that RTAs will be the second most normal explanation behind the powerlessness of carrying on with a healthy lifestyle in coming a very long time for the countries in the year 2020 [44]. A lot of traveler remembering drivers and individuals for foot must have the street use sense. Some other audit also shows that the human part is the explanation of 80 to $85 \%$ of all RTAs. Traffic rules encroachment, banner intersection and nonattendance of driving obligingness, utilization of mobile phones while driving, erroneously halting, negligence of zebra convergence, riding motorbikes without defensive tops and lights, over-speeding, and change of way sans using markers are so fundamental as a piece of Pakistan which are the essential driver of RTAs in our overall population and are the delayed consequences of human exercises. Around $10 \%$ of all RTAs are a result of the risky street and its conditions, while automated insufficiencies are committed for about $5 \%$ of all traffic issues [86].

In a progression of studies, the impact of various weather conditions on transportation patterns and the job of interest the executives to lighten the unwanted results of cruel climate conditions were assessed by Kim, Mahmassani [87], and they stress the significance of joining a prescient framework. The enthusiasm for various unfavorable climate conditions and transport frameworks is clear, with most investigations concentrating on conduct changes or traffic pertinent concerns.

\subsubsection{Impact of Different Climatic Components on Road Traffic Accidents}

Climatic contamination, just as some other climate operators which incorporate haze, ice, precipitation, and snowfall (with related wet and tricky streets and low rubbing and low visibility), temperature, and wind speed and so forth have recognized effect on transportation in urban communities. Also, various investigations referenced that climate factors can build the size and recurrence of street mishaps [80, 88, 89]. Temperature is additionally portrayed as a solid climate specialist, which favors car accidents. Andrey and Yagar [90], Bergel-Hayat, Debbarh [80], and Kalankesh, Mansouri [91] accept that an ascent of $1^{\circ} \mathrm{C}$ in can quicken the frequency pace of car accidents $1-2 \%$ regardless of if the driver takes extraordinary caution while driving on wet streets [90]. Additionally, low air contamination fundamentally influences the air transportation, for example, photochemical exhaust cloud, which causes low visibility, flight delays, and air accidents. 


\subsubsection{Impact of Temperature on Road Traffic Accidents}

The temperature of the atmosphere has a psychosomatic and physical effect on a driver of the vehicle. Essentially, a French report presumed that high events of RTAs are appended with higher temperatures. Further, they detailed that people apparently drive at various conditions of the day, and they restless significantly as a result of high temperature around night time. These results show that they are increasingly depleted when they are out for driving on account of high temperature [92].

The medical reports demonstrated a solid explanation of RTAs and mortalities as a result of high temperatures. In an examination focus setting, it had been indicated that the temperature of $85^{\circ} \mathrm{F}$ didn't impact the speed of the vehicle rather brought about a higher mix-up rate. The higher temperature has been found to impact on following, watchfulness, and performing various tasks while essential acknowledgment and reaction time remains unaffected [93]. In any case, ventilating may direct these impacts [94]. The recurrence and force of RTAs are significantly affected by high temperature extends in like manner on day by day and week after week just as on month to month premise plans [95]. Ordinary occasions of daylight additionally increment the scenes of RTAs [96, 97]; be that as it may, Brijs, Karlis [95] and Bergel-Hayat [98] found that deviation from normal every day and month to month temperature systems improved the recurrence of RTAs. As needs are, Malyshkina, Mannering [99] revealed that RTAs have a positive connection with the predominance of high and low temperatures [96, 98].

\subsubsection{Impact of Rain on Road Traffic Accidents}

Precipitation is always referenced as the climate wonder, which is answerable for the continuous rate of RTAs [100, 101]. Precipitation impacts RTAs through the disappointment of erosion on the street among tire and street surface. In precipitation, diminished visibility and hazardous conditions expanded RTAs rates [102]. Scarcely any prior investigations likewise engaged in the event of RTAs in urban districts in connection to precipitation [103, 104]. Also, striking occurring on the grounds, for the most part at night times, expands the RTAs out and about. Also, striking occurring around night time because the headlights of onrushing vehicles impersonate in the water on the outside of the street [105].

The obscured windscreens as a result of high sogginess amid precipitation can in like manner, increment the deceivability [106]. It has been seen that precipitation, snowfall, and hails decreased the contact on the outside of the street. Dainty water layers on the street surface lose contact between vehicle tires and street.

The chances of water arranging depend on the slipping experience of the street, and the speed of vehicles alongside tire track profundities [105]. Precipitation is continually referenced as hazardous conditions that are responsible for the assorted scope of mishaps connected with precipitation [100, 101]. It additionally diminished visibility on the windscreen. Shower from different vehicles additionally has an awful effect [102] on-street traffic. Nonetheless, better vehicle structure and drivers' training have prompted limit the RTAs all around as of late [101, 107]. Expanding urbanization ventures expanded the unfriendly climate conditions (specifically the precipitation) [108]. In created nations, considers various climate conditions and RTAs, and related loss and damage have a long history. For example, Andrey, Mills [103] information from moderate-sized Canadian urban areas demonstrated that threat of RTAs increments and wounds because of precipitation and precipitation augments the mishaps up to $75 \%$ and related wounds up to $45 \%$, yet snowfall has more broad accident than precipitation.

Eisenberg [109] has discovered that RTAs happened less when drivers know about an up and coming precipitation occasion before going out for an ordinary drive. Also, Brijs, Karlis [95] are certain with the discoveries of Eisenberg [109] proposing that the extent of RTAs increments when it trails a long term drought. Also, levels of toxins during the precipitation, particularly in storm season, were more prominent than those of the non-rainstorm season [110].

\subsubsection{Impact of Fog on Road Traffic Accidents}

Fog in the atmosphere is a recognized climate component with a significant effect on RTAs and the related security measures since it decreases visibility potential at the streets and adversely impacts the driver's discernment, vision capacity, and the choice inclinations. Less visibility is viewed as a key factor in prompting RTAs, and it has been upheld by factual information too. Along these lines, street traffic building specialists need to distinguish and assess the collaboration among RTAs and dependable variables. What's more, the recommended speed limits and the typical traffic volumes in poor visibility areas are viewed as essential elements included in the event site and sort of street mishaps.

Safety strategies and measures can check the dangers of street client's damage and loss. Productivity shows that drivers and vehicles can land at their goals in the given conceivable time. Drivers will, in general, invest less energy in the street by speeding up, however driving in a fast in mist with the decreased visibility can prompt a lower security level and cause RTAs. Along these lines, foggy climate conditions increment street mishaps since they influence the impression of drivers, speed of vehicles, and separation. These impacts likewise decreased complexity as we watch 
things, not so much splendor or murkiness. Also, fog and smoke are appreciated to make dazing driving conditions for drivers; incredibly, little research has been coordinated on the characteristics of murkiness and smoke-related mishaps, and on the occasion of such mishaps all in all national turnpike.

In a fog, the dews of water are nearly nothing and light that they remain floating recognizable all around. It prompts a reduction in see capacity because the light is diffused by the dimness dabs. Overall, fog happens when the moistness is $100 \%$. Exactly when this occurs, people generally drive gradually yet keep up just little good ways from the vehicle they are behind, and in the wake of low visibility, the danger of mishaps gets more noteworthy [106]. Haze can, in like manner, propose sufficient arranging when water dots make a flimsy layer on streets. The mist related mishaps factors in Florida were contrasted with clear visibility crashes impact components, and this examination indicated a noteworthy difference between hazes related mishaps and clear visibility conditions in street mishaps seriousness and crash type [111].

\subsubsection{Impact of the Low Sun (Glare) on Road Traffic Accidents}

Visibility is a fundamental requirement for safe driving; any misconception in a driver's vision because of light can meddle with the driving undertaking and force a risk. Along these lines, sun glare is one of the significant elements which cause vision impediment. Headlamps of the vehicle are by all account not the only wellspring of glare yet additionally in some cases, daylight and headlamps of the vehicle may likewise hinder a driver's vision and become a causative factor to a street mishap. At the point when drivers drive in high sun scowl conditions, low sun, or expected headlights in the night, the visibility of things are minimized and differentiate the fate of the articles or items might be too little even to consider seeing [112]. A principle reason for the difficulties connected with daylight is that light is sprinkled onto the retina of the eye and decreases the differentiation of the retinal picture [113]. A decrease conversely is named as an inability to sun glare. More often than not, drivers experience trouble to see things unmistakably external their vehicles when there is low sun commonness. However, a few drivers get them far from introduction to high sun glares.

Most drivers realize that headlights and low sun can make progressively confused to see things obviously [114]. Glare defenselessness test is appropriate for recognizing the gathering of drivers who are powerless against sun glare $[115,116]$. A solid proportion of a person's sun frown at lab level presentation and the event of RTAs in higher sun glare circumstances is more uncertain articulated. It isn't assessed at this point at how a lot of potentials and power sun glare can affect the driving ability. In any case, these glares are viewed as irksome to the security of senior drivers. Babizhayev [115] showed that right now, none of the investigations demonstrated that more noteworthy inability glare is freely connected with street mishaps or trouble in driving. Thus, by and by extensive holes lie in our insight seniorage residents [116] are increasingly defenseless against the elevated level of glare powerlessness, and among them, the more conspicuous gathering are the casualties of eye waterfalls [117]. Additionally, as indicated by a past report, the powerlessness of drivers with over 65 years of age will be expanded from 1 of every five during 2030 [118]. There are solid logical inconsistencies in previously mentioned discoveries because Zhang, Jiang [116] expressed that an incredible deviation, for the most part, exists between age bunches because of the way that even some youthful drivers have increasingly visual incapacity in this way they have more vulnerability towards sun glare than a lot of old drivers.

From this time forward, the sun glare inability can strengthen and guarantee better wellbeing of drivers, having a place with all ages, at streets by adjusting an unrivaled getting approach. An examination has been directed in Japan to discover the commitment of sun glare in RTAs [119, 120]. Depicted that the frequency of RTAs, as a rule, goes higher when sun presentation was before engine vehicles than the person on foot mishaps [121]. They likewise saw that RTAs happened with more noteworthy recurrence when the vehicle has a direct front introduction towards the sun. In talking about the frequency of RTAs as for vehicle type [122], the study likewise depicted that sun glare doesn't build the likeliness of mishaps in the event of overwhelming vehicles; in any case, it positively contributed the mishaps wherein engine vehicles with two wheels. During assessing the obligation of RTAs timing in Arizona, USA, Mitra [123] inferred that RTAs were going on more now and again at first light to sunset than different occasions of a regular day.

Though, this investigation has a few provisos that scrutinized the unwavering quality of the end. Among those escape clauses, initially, the main four classes (north, south, east, and west) of voyaging street headings were just settled in this examination. Also, the timetable at which the effect of sun glare on RTAs event was recorded, and it just restricted to $1 \mathrm{~h}$ after and before dawn and dusk separately.

Thirdly, climate conditions were not examined and evaluated the sunlight based situation during RTAs, and they prescribed a strategy to decide the impact of sun glares on street mishaps rates [124]. The antagonistic impacts of sun glare on the passage exits were considered, and the proper street plans were shown as the keen decisions to keep from the sun glare-activated RTAs [125]. Daniel and Chien [126] referenced that vehicle during daybreak and sunset moderately at more slow speed in contrast with different occasions of the day. First light and sunset can colossally hinder the view that road customers have different exercises in lanes. The sun blinds the most when it is low just 
around the corner. It is the circumstance until around an hour after daybreak and from around an hour before nightfall. Drivers can look at a present glance through their windscreen, yet can't see indisputably any more. Also, roundabout sunshine, which is copied by reflecting, for example, a glass building, uproar limits, or distinctive cars, can be perilous. Right when light by the sun, the street on the windscreen is progressively perceptible, as such upsetting driving. Elements like wet roads surface or mirrors at sunshine are top occasions for light deceivability [106].

\subsubsection{Impact of Air Pollution on Road Traffic Accidents}

Anthropogenic air contamination and its comparing increased RTAs, for the most part, have a reasonable impact relationship. However, it has been broadly comprehended that air contamination is extraordinarily answerable for harming human wellbeing, yet it is likewise a prevailing variable that diminishes the security on streets. Then again, traffic blockage has likewise upraised, which is connected with mechanical and national advancements [127] even though traffic itself makes air contamination. The air contamination is chiefly ascribed to overwhelming street transport, overpopulation, and inordinate vehicle use, too high life gauges. Different epidemiological examinations featured the syndication between the degree of air poisons and comparing recurrence of routine passing's and medical clinic inductions just as possibility room visits. Traffic discharges have noticeably shown up with hurtful effects on general wellbeing by falling apart the personal satisfaction [128]. Also, various sorts of concoction mishaps are among the recognized drivers of air contamination, prompting ecological tainting and financial misfortunes too [129-131]. Among different toxins, the little particulate issue is a recognized one that is a mind-boggling composite of various substances and are an essential or auxiliary class of particulate issue [132]. Cold months are prevailing time spans with evident infringement of air quality gauges because of a join increase in household warming patterns and street traffic emanations [133-136]. Also, unnecessary scenes of haze additionally increment the recurrence of street mishaps [88]. It has been proposed that poor air quality is answerable for causing aggravation in the nose and eyes of drivers, which results in less concentration and interruption from the driving. Correspondingly, Auffhammer, Fan [137] said that air contamination is a prevailing component that impacts driver practices prompting extreme street crashes.

World Health Organization has detailed that in 2013 roughly 1.24 million passings over the globe are credited to RTAs [4]. A few investigations have portrayed that RTAs will turn out to be second or third unmistakable passing variable in both higher-and center salary nations with all-out life misfortune drawing closer to 2 million. Besides, creating nations are likewise significantly powerless against these RTAs $[8,138,139]$.

\section{Research Methodology}

The information collection and investigation in this report utilizes an inductive way to deal with comprehend the dangers and reasons for overwhelms in super tasks in Pakistan. This area gives a brief subtleties of the strategy used to gather information and investigation. Since this examination expects to investigate dangers characteristics in different periods of megaprojects, i.e., arranging and improvement and execution of various phases of megaprojects in Pakistan, it appears to be suitable to embrace a conducted way to deal with have profound understandings of emotional contemplations of open area authorities, development firms/contractual workers and counseling organizations. This investigation embraced expansive subjective methodology [180-182], because quantitative examinations have constraints of lacking abstract musings and point of view of respondents, about the marvel of overwhelm in ventures. Therefore, to explore factors causing RTAs in Pakistan, this study explores young adults who have met some RTA in the recent past. A screening questionnaire was to be used to identify potential participants to identify the factors that modified the attention behavior of young while driving. All the participants were treated as per the ethical standards set by the University of Engineering and Technology, Taxila. The introduction and objectives of this study had been shared with participants requesting them about their availability for interviews and venue. Participants were drawn nearer by and by the questioner (the principle researcher), and the examination object was clarified verbally. A data sheet was given if individuals indicated enthusiasm for taking an interest. All meetings were sound recorded with the assent of the participants. Figure 1 shows the Flowchart of the research methodology.

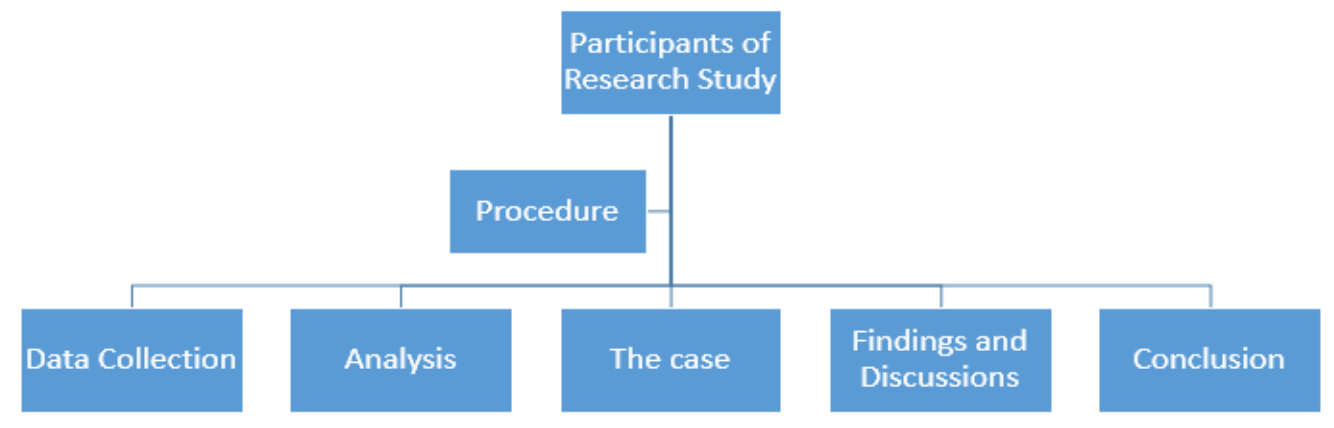

Figure 1. Flowchart of research methodology 


\subsection{Research Participants}

By adopting an in-depth ethnographic methodology, twenty in-depth interviews were conducted in Islamabad, Rawalpindi and Taxila. Participants of this study were young adults who were university students and have met some RTA and could have better bits of knowledge to explain the circumstances that led to RTAs. Participants went in age from 16 to 24 years (median age $=21$ years). In the beginning phases of the information accumulation about this study, a different example had been reached to coordinate the way that present writing has investigated RTAs, witnesses, and those who called for emergency medical for moving and treating the victims, alongside rescue workers working with Rescue Service 1122. In this manner, this investigation began with convenient sampling to start with and afterward embraced a purposive inspecting methodology [183]. Every one of the participants of this study was located at Islamabad, Rawalpindi,and Taxila cities of Pakistan and spoke to those who have met RTA. Three types of subjective examining were utilized: purposive (choosing specific gatherings), standard (experienced in street use in Pakistan), and snowball. Twenty participants (18 male and two female) had been identified through a screening questionnaire, out of which one strict speaker (included during the examination as a result of issues of elucidation of religion that rose during the meetings) were enrolled through close to home and professional contacts of the principal researcher. The map showing study area is shown in Figure 2 Also the demographic characteristics of the participants are given in the Table 2.

Even though theory suggests examining to the point of theoretical saturation in qualitative data collection [184], in real-life financial reserves are looking for explicit example measures that, for the most part, must be contended and advocated preceding receipt of assets and any enrollment of members. Subsequently, the number of drivers to meet in this study was at first dependent on earlier investigations of this nature. Immersion, that is, where a foreordained number of back to back interviews (regularly set at 2 or 3) stop to yield new material of intrigue, might become to as ahead of schedule as after six meetings [185].Furthermore, along these lines, this number was utilized as the reason for the example size for each age bunch in this examination. By and by, there was the chance to do additional meetings in the vast majority of the age gatherings (an extra 5 in general), be that as it may, immersion was at that point clear for most subjects before these additional meetings. Participants from various cities were incorporated to give a wide scope of perspectives on the issues under scrutiny. Most of the participants revealed having been engaged within any event one accident and pretty much every participant announced that family members, companions, as well as associates had been seriously harmed in RTAs. This taxonomy outlines five classes of riding mistakes together with five classes of informal elements (See Table 3).

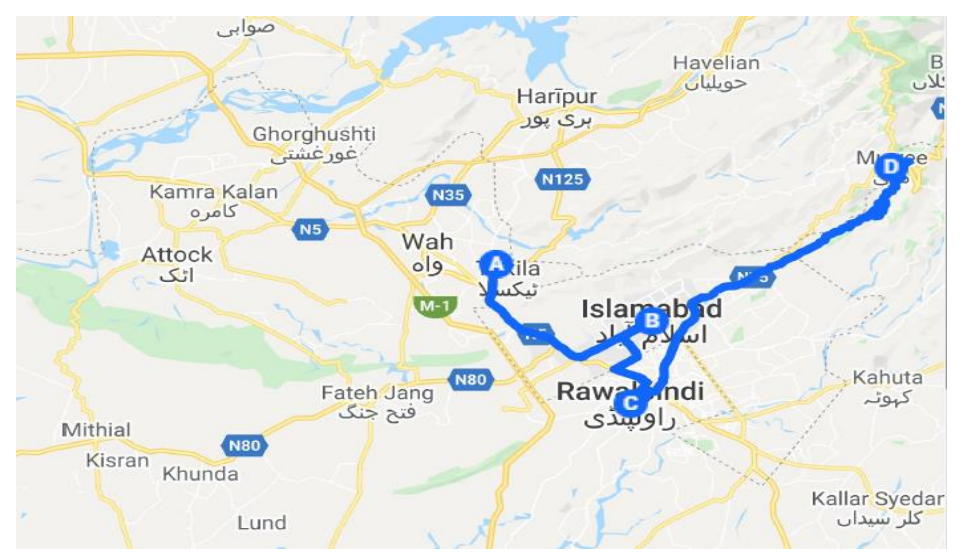

Figure 2. Map Showing the Research Study Area

Table 2. Demographic characteristics of participants of the study

\begin{tabular}{lc}
\hline Demographic characteristic & Number of participants \\
\hline Gender & 18 \\
Male & 2 \\
Female & \\
Religion & 19 \\
Muslim* & 1 \\
Christian & \\
Education level & 20 \\
Tertiary education** & \\
\hline
\end{tabular}

*Islam is the state religion, and approximately $97 \%$ of the population identifies as Muslims

**All the participants of this study were university students 
Table 3. Driver Error Taxonomy including Underlying Psychological behavior

\begin{tabular}{|c|c|c|}
\hline Psychological Behavior of Human being & External Error Made & Examples \\
\hline \multicolumn{3}{|l|}{ Action errors } \\
\hline Action execution & Fail to act & Fail to check rear view mirror \\
\hline Action execution & Wrong action & Press accelerator instead of brake \\
\hline Action execution & Action mistimed & Brake too early or too late \\
\hline Action execution & Action too much & Press the accelerator too much \\
\hline Action execution & Action too little & Fail to press the accelerator enough \\
\hline Action execution & Action Incomplete & Fail to turn the steering wheel enough \\
\hline Action execution & Right action on wrong object & Press accelerator instead of brake \\
\hline Action execution, planning and intention & Inappropriate action & Following too close, race for gap, risky overtaking \\
\hline \multicolumn{3}{|l|}{ Cognitive and decision making errors } \\
\hline Perception & Perceptual failure & Fail to see pedestrian crossing \\
\hline Perception & Wrong assumption & Wrongly assume a vehicle will not enter path \\
\hline Attention & Inattention & Nearly hit car in front when queuing \\
\hline Attention & Distraction & Distracted by secondary task \\
\hline Situation assessment & Misjudgement & Misjudged speed of oncoming vehicle, misjudge gap \\
\hline Perception & Looked but failed to see & Looked at roadway but failed to see pedestrian \\
\hline \multicolumn{3}{|l|}{ Observation errors } \\
\hline Memory and recall & Failed to observe & Failed to observe area in front of vehicle \\
\hline Memory & Observation incomplete & Failed to observe side mirror when changing lanes \\
\hline Situation assessment & Right observation on wrong object & Failed to observe appropriate area \\
\hline Memory and recall & Observation mistimed & Looked in drivers side mirror too late when merging \\
\hline \multicolumn{3}{|l|}{ Information retrieval errors } \\
\hline Situation assessment & Misread information & Misread road sign, traffic control device or road markings \\
\hline Situation assessment & Misunderstood information & Perceive information correctly but misunderstand it \\
\hline Situation assessment & Information retrieval incomplete & Only part of required information retrieved \\
\hline Situation assessment & Wrong information retrieved & Read wrong information from road sign \\
\hline \multicolumn{3}{|l|}{ Violations } \\
\hline Action execution, planning and intention & Intentional violation & Overtake on double lines, intentionally exceed speed limit \\
\hline Action execution & Unintentional violation & Unintentionally exceed speed limit \\
\hline
\end{tabular}

\subsection{Procedure}

All the participants were treated as per the ethical standards set by the University of Engineering and Technology, Taxila. The introduction and objectives of this study had been shared with participants requesting them about their availability for interviews and venue. Participants were drawn nearer by and by the questioner (the principle researcher), and the examination object was clarified verbally. A data sheet was given if individuals indicated enthusiasm for taking an interest. All meetings were sound recorded with the assent of the participants.

\subsection{Data Collection}

A qualitative approach is considered suitable due to the nature of the study, which requires detailed views of subjects [180] to investigate varying perspectives on the causes of RTAs [183] due to limited literature to date [186]. Semi-structured interview format deemed appropriate to explore the behavioral perspectives of the participants of the study and reduced effect of the investigator; an interview guide had been developed using open-ended questions. An interview guide is prepared for participants, using standard techniques of semi-structured interviews [187].A copy of the interview guide is attached as Appendix - II. Participants were approached to examine their frames of mind and convictions about driving, crash causation, and street use. Sound chronicles were interpreted and deciphered by a different interpreter utilizing the idea of importance interpretation [188]. Another bilingual expert in the research checked an arbitrary example of transcripts to guarantee the legitimacy and respectability of the retrogressive interpretation process [189]. The principle researcher checked the interpretations against the accounts for legitimacy and unwavering quality. All the participants of this study were guaranteed to upholding the confidentiality of the interview data; written consent was acquired from the participants for audio-recording of the interviews. A copy of the 
informed consent form is provided in Appendix - III. A total of twenty interviews had been conducted to explore the answer to the research question of this study. Eighteen of the participants of this research study were male and two were female and pleased to provide input for this research. Most of the interviews were conducted at the time and venue that was convenient to the interviewee, which in this case, was a discussion room in the library at the University of the Participant of the study in most of the cases.

Interviews began with a brief description of the study, asking for the written informed consent of the participant to the audio-record discussion of the interviews. The meeting cum discourse meeting endured in the range from $25-45$ minutes span. Every one of the meetings began with a clarification of the investigation, and an educated assent was acquired from the interviewees. In the wake of getting educated assent, every one of the meetings was sound recorded. Sound chronicles were then interpreted for examination. Transcription brought about an archive containing thirty-eight thousand three-hundred seventy-nine $(38,370)$ words documents. Transcripts were broken down utilizing topical examination [190], and investigations were attempted with the aim of comprehension, not of forecast [191]. Remarks made by members about their convictions are their very own and don't comprise judgment or proclamation by the creators. For instance, it is past our skill to remark on whether a member's elucidation of their religion is right or not. The progression of words and typical statements were saved where conceivable. A coding structure was created to secure the character of the meetings, i.e., by evacuating genuine names or individual distinguishing proof information from the interpretation utilized for examination.

\subsection{Analysis}

Transcribed information of recorded meetings was moved to programming for investigation utilizing QSR's NVivo, version 10. Analysis to identify themes [192], utilizing an interpretive system, was directed by the primary creator on the transcripts of the meetings. The investigation started right off the bat in the meeting procedure and proceeded at the same time with on-going meetings, enabling later meetings to investigate key topics recognized in the previous meetings. In the initial step of this procedure, every transcript was painstakingly inspected to recognize content talking about ideas that gave off an impression of being basic or intriguing, which were then given marks [192]. As the assessment of the transcripts advanced, there was likewise a quest for expansive examples of experience [193] showing up over the meetings both in connection to the particular research interests just as other, unexpected or emanate issues. Considering and deciphering, these together permitted the identification of the key topics. After this, the subsequent advance was the identification of those segments of every transcript that identified with these wide topics, trailed by identification of key subthemes and ideas inside every principle subject. Inside this procedure, anyone bit of content could be sorted as having a place with more than one topic or subtheme since the content parts were at the degree of entire sentences or passages. As distinguishing proof of the topics depended on the underlying investigate premiums in driver contemplations and feelings associated with scenes of contention out and about, the examination was in part deductive [192]. Nonetheless, as referenced above, topics were allowed to develop all through the meeting procedure, subsequently presenting a semi-inductive examination.

\subsection{The Case}

This research adopted a thematic analysis approach, which is generally used in qualitative investigations. Thematic analysis categorizes, unifies, and conveys meanings to patterns seen systematically from the data [190]. A coding structure was developed and used to conceal the names, or personal identification was used in the analysis to maintain the anonymity of the interviewees. The first part of the code characterizes the number of the participant, and the second part labels their university they are studying. The third part of the code represents the time (in years) they met an RTA. For instance, a person year who had been contacted at a university one met an accident about two years ago is coded at P1U12. Details of the interviews of the participants of the study are given in Table 4.

Table 4. Details of the interviews of the participants of the study

\begin{tabular}{ccc}
\hline Persons & Age Group (Years) & Interview Transcription Word Count \\
\hline P1U12 & $16-18$ & 1943 \\
P2U11 & $18-20$ & 1745 \\
P3U23 & $18-20$ & 1760 \\
P4U11 & $20-22$ & 2106 \\
P5U12 & $20-22$ & 1873 \\
P6U23 & $22-24$ & 1975
\end{tabular}




\begin{tabular}{lll} 
P7U31 & $20-22$ & 1918 \\
P8U32 & $16-18$ & 1990 \\
P9U31 & $20-22$ & 1901 \\
P10U31 & $18-20$ & 1881 \\
P11U12 & $18-20$ & 1950 \\
P12U11 & $20-22$ & 1870 \\
P13U21 & $20-22$ & 1839 \\
P14U13 & $22-24$ & 1951 \\
P15U21 & $20-22$ & 1830 \\
P16U23 & $20-22$ & 1931 \\
P17U22 & $20-22$ & 1911 \\
P18U31 & $20-22$ & 2001 \\
\hline P19U31 & $20-22$ & 1961 \\
\hline P20U31 & $20-22$ & 1943 \\
\hline Total Persons & & Total \\
\hline 20 & $\mathbf{3 8 , 3 8 9}$ \\
\hline
\end{tabular}

Hierarchical codes were developed from the literature to begin the analysis of this study. The underlying investigation utilizes these codes and distinguishes fundamental topics and thoughts from perusing the writing on invade in megaprojects. In the wake of bringing in deciphered meetings in QSR's NVivo version 10,initial examination looks at various examples that used to upgrade the coding by utilizing fundamental topics and ideas recognized from the transcripts into an ordinal structure by following the rules of Charmaz and Belgrave [194]. After the underlying investigation, the progressive coding plan is modified, given the recognized examples in the informational index. The investigation of examples in the transcripts uncovers subjects and sub-topics. A short time later, a similar procedure was completed to assemble every single comparative theme of discourse under one significant gathering. Interpretations were inspected to guarantee the fitting of every datum thing in the particular hub. It was an iterative procedure and prompted visit development between created hubs and transcripts. A coding plan was reviewed, and it drove refining subjects distinguished first and foremost after the underlying examination. Appendix 4 details the final coding structure followed in the analysis of data collected for this study. The analysis revealed that there is a substantial understanding of the dynamics of the vehicle at hand and traffic conditions of various roads or highways; however, little focus is given to factors that have the potential to lead to RTA. Most frequent words used by the participants are; distractions, speeding, reckless driving, road rage, pedestrians, weather, potholes, tire blowouts, brakes, night time driving, unsafe lane changes, sleep-deprived, rain, and running red lights. Most frequently cited words in the data set are given in Figure 3.

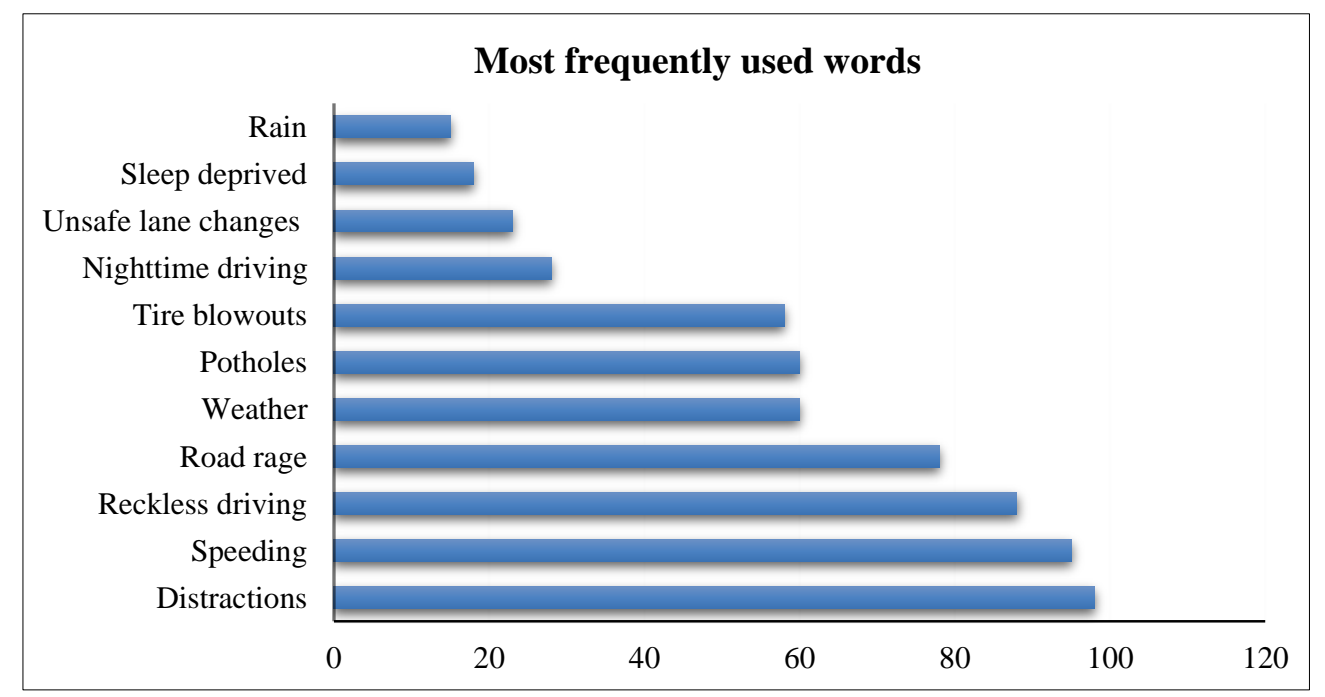

Figure 3. Most frequent words used by participants during Interview 
The analysis of transcribed data based on most frequently used words reveals important underlying reasons that cause RTAs in Pakistan. Driving distractions came out to be the most cited word in transcriptions. Some of the common driver distractions are given below;

- Talking on a mobile phone;

- Sending instant messages;

- Reaching for a moving item inside the vehicle;

- Looking at an article or occasion outside of the vehicle;

- Reading a book/magazine;

- Eating a snack or meal;

- Applying cosmetics.

These facts are also indicated by Hagita and Mori (2011) [118] eighty-percent of car crashes and sixty-five percent of close mishaps include probably some driver interruption inside three seconds of the crash or approaches miss. Distracted driving takes one's eyes off the road, and drivers that redirect their mindfulness - regardless of whether it's to chat on their mobile or send instant messages to their friends -hazard the lives of different drivers out and about. Driving distraction is particularly hazardous because, though flushed driving, for the most part, happens around evening time; car crashes brought about by occupied drivers can throughout the day. It happens when one considers activities in the vehicle, other than simply driving, one can see that they regularly include more than one sort of interruption. For example, on the off chance that you change your music player, in addition to the fact that you take your hand off the guiding wheel to press a catch, however, one additionally takes the eyes off the street to see what button is needed to press. Likewise, drivers who connect all the more regularly in diverted driving are bound to be engaged with a car crash or approach crash.

Distractions in driving due to mobile phone usage are higher for drivers who are intensely occupied with phone distractions. Examples of mobile phone usage could be;

- Dialing a mobile phone expanded the danger of a fender bender or close to a vehicle crash;

- Talking on a mobile phone increased the danger of a vehicle crash or approached a collision.

The headset or Bluetooth mobile phone isn't more secure than hand-held mobile phone utilization. Voice enacted frameworks are, be that as it may, less dangerous if drivers need not take their eyes off the road or hand off the steering wheel regularly or for significant periods. Send text messages while driving is really dangerous. Text messaging while at the same time driving can make a genuine accident scourge.

Distractions in driving affect teenage drivers more as opposed to grownups. Another significant kind of distraction is eating in the vehicle while driving; one is concentrating on nourishment and not out and about. Not exclusively is biting and gulping occurring. However, one is additionally opening bundles, unwrapping and re-wrapping nourishment, coming to, inclining, spilling, cleaning and cleaning oneself or vehicle.

Speeding is the second most cited word in the interactions with the participants of the study. The quicker the vehicle speeds, the less time one needs to respond - also the expansion in powers on the human body in an RTA at high speeds. Also, individual injuries are more regrettable in accidents caused at high speeds. It is intentional and determined conduct where the driver realizes the risk; however, it overlooks the risk. Also, excessive speed is not the only problem; consider the example shared by a participant; a walker ventures into a crosswalk with a moving toward a vehicle that is going around $50 \mathrm{Km} / \mathrm{hour}$. If the driver brakes when the passerby is 45 feet away, there will be sufficient space to stop without hitting the person on foot. The drivers who engage in speeding often drive recklessly and show a dismissal for the guidelines of the road. Also, it involves more than one traffic violation and leads to the following;

- Causing a car crash;

- Distracted driving;

- Drinking and driving;

- Driving without headlights;

- Improper turns;

- Running red lights;

- Speeding;

- Sudden braking;

- Tailgating. 
While speeding alone isn't typically viewed as crazy driving, an amazingly high pace may lead to careless driving and one may indulge in other elements listed below;

- Presence of a person on foot traffic;

- Time of day;

- Traffic conditions;

- Visibility;

- Width and surface of the roadway.

It is important to note that young drivers often engage in reckless driving. It is especially the case when parents or guardians are far out, young university students who are simply beginning to figure out the road - take part in careless driving conduct to dazzle their companions and test their breaking points. They need to be "cool" and part of the gathering, and they test their breaking points and common desire to impede sound judgment. It is for this reason they often experience road rage. Teenage drivers who get a fresh license and get vehicles to attend university/ college are destined to cause RTAs. The fatalities in vehicle crashes for young male drivers are approximately one and a half times that of female, young drivers. The inexperience of the young drivers often leads to car accidents, some of the factors are listed below;

- Teenage drivers are almost certain than more seasoned drivers to think little of unsafe circumstances or are essentially unfit to remember them;

- Teenage drivers are likewise the age bunch doubtlessly not to wear a safety belt, which makes their injuries and demise sums into vehicle crash far more awful.

Rain and severe weather conditions have been the reason for a large number of vehicle collisions every year, and the downpour is particularly risky in dry climate areas of the country. Numerous individuals overlook how to in it. Hence, drivers need to see precisely how downpour can cause a car crash. A lot of drivers don't know how to drive in the rain. In awful weather conditions, there are two kinds of drivers who can altogether build a hazard to other people; unreasonably hesitant drivers and wild drivers. Too many hesitant drivers would, in general, overestimate the peril of climate conditions and drive to irrationally low speeds. At the point when as far as possible, the number of accessible traffic paths, for example, can happen following overwhelming precipitation, this sort of diver can make traffic back up, increasing the risk of a backside mishap. Many young drivers overlook the results of terrible climate and may even think it is ideal that the climate has constrained a ton of different drivers off of the road. The exuberance of youth and joyfulness brought by the young passengers entice them to be reckless drivers who may well drive at full parkway speed or more noteworthy, in any event, when visibility is low or the streets are doused. Once such drivers lose control on a dangerous street, their speed makes it substantially more likely for an RTA to happen.

The slipperiness of the roads due to downpour makes it increasingly hard to remain on a roadway, to stop, or to abstain from slamming into different vehicles. It is particularly obvious when it first starts coming down because streets are generally tricky toward the start of a rainstorm. At the point when the road initially gets wet, oil ascends to the surface and makes an oily surface. If one can't stop your vehicle in time, that is when a mishap occurs. Rain and windstorms, especially in the monsoon season, significantly decrease visibility, and it tends to hard for drivers to see different vehicles. At the point when the downpours joined with filthy water kicked up from the roads by different drivers, windshields can immediately get messy.

Driving in the late evening is one of the top reasons for vehicle accidents, as a blend of the headlights and street lights adds haziness and can cause issues for the vision of the drivers. Driving when one is tired is another additional threat, especially in the evening, as individuals are commonly unwinding their days and becoming drowsy.

Unsafe lane changes are also one of the identified reason of RTAs when one erroneously moves into another lane without verifying whether a vehicle is in the following path or passing a vehicle without checking the approaching traffic, and before you know it, one of the top reasons for RTAs has occurred, when unsafe lane changes combine with other factors like speeding, inexperience, and at worse road rage, especially in the presence of bad weather conditions, the probability of occurrences of RTAs increases exponentially.

Potholes are bowl-openings in the street that can up to 10 inches down and a brought about by the mileage and enduring of the roads. These are formed when the top layer of the road, the black-top, has eroded and uncovered the solid base. When a pothole structures, it can develop to a few feet, with downpour water quickening the procedure and making a snare for vehicles, making one of the top reasons for RTAs. Potholes put an immense strain on vehicle suspension and stun, which assimilate the greater part of the effect of knocks and potholes. Potholes do costly harm to vehicles. A Street covered with potholes can cause property harm to the vehicle and cause RTAs, especially when drivers are a novice and traveling in the area for the first time. Potholes cause not only car accidents but also fatal motorcycle accidents. Generally, when a pothole is so extreme, the vehicle and driver aren't prepared to deal with the 
blow, which is as heavy as big or deep as the pothole is. Motorbike drivers are at exceptional risk of damage if they ride over a pothole - similarly, trucks and cars at additional risk of collision in the wake of running over a pothole.

Sleep deprivation and tiredness of drivers normally alludes to driver weakness or sleepy driving. It has also been found among the top reasons for vehicle RTAs since sluggish drivers can't satisfactorily see, respond and react to circumstances out and about. Especially in the case of young drivers, when they feel more energetic and excited, they ignore the demands of rest posed by tiredness instead continue to drive. In extraordinary cases, the driver may fall into micro sleep and quickly lose awareness out and about. The tiredness of young drivers is of significant importance as they tend to get recognition of the accompanying passengers and want appreciation for being energetic and active and try to conceal the real tiredness. Drivers' exhaustion can be identified through the following actions;

- Yawning;

- Tired eyes;

- Boredom;

- Inability to recall headings;

- Restlessness;

- Difficulty in concentrating.

\section{Results and Discussion}

This study shows that casual, positive affect enlistment prompted a lower eagerness for risky driving when contrasted with acceptances of aroused positive, negative, or nonpartisan effect. Negative influence induction, on the other hand, prompted a higher ability to go out on a limb out and about than a casual positive or nonpartisan influence enlistment. It validates the past research demonstrating the potential damage that may come about because of utilizing negative feelings to impact social change [195], and proposes that utilizing negative affect is subject to have a boomerang impact, elevating youths' ability to risk [169]. The principal commitment of the present investigation is that it proposes another option. Following past investigations, e.g., Taubman-Ben-Ari [23], the outcomes bolster the possibility that casual, positive affect acceptance may fill in as a powerful method for diminishing the propensity of youthful drivers to drive foolishly. Messages utilizing positive feelings may give a model of safe conduct by fortifying attractive social standards, and might be more beneficial than those exciting negative feelings through the delineation of the results of risky conduct, following quotes make it clearer.

"... when I engaged in racing with a friend on return after [a] workout at [the] gym, I could not notice the car in front of me was moving at normal speed and tried to clear my way by moving into slow-speed lane, and I bumped in it while attempting to overtake it from [the] wrong side..." (P2U11).

“...I struck my car when a few years back returning from Eid shopping, and [the experience] helped me become [a] good driver...just being so much aware, the fact that anything can come out of nowhere..." (P7U31).

“...I know had I controlled my excitement; I could have avoided it...” (P9U31).

Moreover, the discoveries show the significance of recognizing various kinds of positive feelings. The impact of exciting, positive influence acceptance was seen here as the same as that of negative or impartial influence enlistments, and no change in conduct expectations developed. Likewise, excited, positive influence expanded the ability to drive foolishly, when contrasted with the casual, positive effect. This study in this manner shows the benefit of looking at the impact of distinctive positive feelings in the push to decrease unsafe driving and is by ongoing cases in regards to the significance of the passionate component in altering the conduct of different sorts [196].

"...it is very common to think it is natural that when you ignore the traffic conditions and drive as per your feelings..." (P6U23).

\section{Gender contrasts}

This investigation not just affirmed the presence of contrasts among males and females concerning chance-taking behind the wheel [17], yet also demonstrated that influence acceptance influences youthful male and female drivers differentially. Among youngsters, negative influence expanded the eagerness to drive foolishly, while the impact of loosened up positive influence was the same as that of an unbiased influence enlistment. Interestingly, the readiness of young ladies to drive wildly was not elevated by negative effect, yet was directed by loosening up positive effect.

“...I always take great care when driving even when giving a ride to classmates..." (P13U21).

“...I don't think my attention to driving would be more altered by the comments of the passengers...” (P13U21). 
"...Drivers are predominantly mindful in the occurrence of street crashes as they are pompous. They want to take their vehicle from any niche and corner to the next spot. There has consistently won a desire to lead the traffic..." (P13U21).

\subsection{Driving Relevance to Self Esteem}

As anticipated, driving relevance to self-esteem was emphatically related with the eagerness to drive carelessly. The thematic analysis further helps to discover, uncovering the importance of driving relevance to self-esteem made a special positive commitment to anticipating the readiness for foolish driving. Without a doubt, the discoveries overall demonstrate that youthful drivers' hazard taking doesn't get exclusively from naiveté, absence of expertise, or irregular conditions, but instead satisfies certain formative needs.

Moreover, the significance of driving relevance to self-esteem was found to direct the connection between influence condition and the inclination for chance taking out and about. Those low on this variable detailed less ability to drive wildly following loose positive influence acceptance than after some other enlistment; negative influence enlistment was pursued among them by an expanded eagerness to drive recklessly when contrasted with the casual positive and impartial influence acceptances, however not when contrasted with stimulated positive influence enlistment. Also, stimulated positive influence enlistment was trailed by an expanded eagerness to reckless driving when contrasted with the loosening up positive and nonpartisan influence acceptances, yet not when contrasted with negative influence acceptance. Therefore, youthful drivers with a low pertinence of heading to confidence were most impacted by a casual, positive effect, which is perfect with their detachment to the rushes of driving. Interestingly, among those high on the significance of heading to confidence, loosened up positive influence acceptance was trailed by a lower level of ability for crazy driving just when contrasted with negative influence enlistment. From a viable perspective, it might be presumed that paying little mind to the particular ramifications for confidence, a loosening up positive influence acceptance, would be advised to security results that the three different conditions. Besides, these discoveries underline the risk associated with the utilization of messages containing either negative effect or invigorating, positive effect, the two of which seem subject to deliver a similar bothersome outcome: an ascent in the eagerness for wild driving.

Likewise, the discoveries paint an upsetting picture that warrants an increasingly exhaustive examination. Youthful drivers low on the pertinence of heading to confidence would appear to be impacted more by enthusiastic messages than those high on this variable. It is of specific significance in perspective on the way that the last gathering all in all shows a more prominent readiness for risk-taking as drivers. In this manner, youngsters high on the importance of heading to confidence are at most serious hazard for two reasons: from one viewpoint, they will in general drive all the more foolishly and are subsequently a significant objective of mediations and open battles, nonetheless, then again, they are less affected by such messages. Subsequently, future examinations need to attempt to pick up a more profound comprehension of this populace to find what may, indeed, impact them, and in this manner, to empower the structure of suitable projects for improving their wellbeing. It ought to be noted, be that as it may, that as the impact of directing the pertinence of heading to confidence still can't seem to be explored, further examinations are expected to affirm our clarification. Some quotes from the interviews are given below;

"...I feel confident when I drive my latest car.... I always try to drive ahead all of my friends when going with them to some outing..." (P13U31).

“...just because I have [a] new car, I feel more confident...” (P17U22)

“... Class fellows judge on how we drive, so I feel thrilled to get their praise..." (P15U21)

“...I feel more comfort[able] when driving myself my heavy motorbike on highways..." (P20U31)

\subsection{Driving Relevance to Sensation Seeking}

The theory anticipating a positive relationship between sensation seeking and the eagerness to drive foolishly was likewise affirmed. This is reliable with various past investigations indicating that sensation seekers are bound to make open doors for risky risking and go out on a limb of different sorts, including when driving [197]. One clarification of this conduct in writing holds that even though sensation searchers can reasonably evaluate the peril associated with a given action, they are prepared to go out on a limb to encounter the rush that accompanies it. As it were, risk-taking stimulates vibes that abrogate the conceivably negative results, making the individual dismissal the peril [198].

“...I was driving our new car when going to drop my younger siblings to the bus station when they were leaving for a college trip, in an attempt to show them the driving skills I got, I changed lanes very frequently and ignored a fullyloaded truck coming from behind when I changed lane and stopped due to red-light. The truck struck into our car at high speed and crushed the whole trunk of my car....only after this accident, I realized that fully loaded trucks have long-distance of stopping at emergency when compared to cars..." (P4U11). 
“... I think it was sudden and fate as we were going enjoying the music, and [everyone] was happy on the way back [from] welcome party...” (P6U23).

"...friends in the back seat were controlling the music player to check new sound system [installed] and sound damping done, a few weeks ago...I felt excited when my friends praised [the quality] of the new music player and amplifying system...I felt confident to drive at higher speed..." (P16U23).

“...my dad and mom knew that I did it, and they always tried to make me understand the dangers of reckless driving... They told me that I could have avoided the accident and ruining my life...it took me over a year to walk again without [any] support..." (P14U13).

"...if you know your friends well and get them in your car; then you must be able to control your driving attention...I learned it after the collision, as I felt excited to drive with high risks when speeding and crossing [changing] lanes in an unsafe manner..." (P8U32).

Moreover, the present findings demonstrate a directing impact of sensation looking for on the connection between influence enlistment and the readiness to drive carelessly. It proposes the impact of the acceptance was not reliant on the individual variable, yet had a critical impact past this worldwide character attribute. The consequences of the relapse examination give proof to this decision, indicating a noteworthy special commitment to influence enlistment past sensation chasing. These findings further validate the conflict that the impact of effect acceptance is more grounded and more successful than that of different messages [196]. One of the participants revealed following in the interview;

“...we went for a party on Eid night...one of [my] friends drove us home. He was OK, and all of sudden he started driving crazy; we thought he was speeding but he was racing with another car...we crashed just before anyone of us could realize what is going on..." (P17U22).

"...my accident on main road primarily occurred because of a van driver. They are the worst drivers. Bus drivers are also not good but a van driver can even overtake him to collect passenger... he did not even bother to give enough room to me to pass [overtake] him before he stopped to pick up a passenger..." (P19U31).

There was important revelation by the participants as most of members saw themselves to be vulnerable as to destiny and fate and communicated the conviction that destiny alone decided their life course. They may accept different elements could help, similar to their own behavior, yet these could possibly work whenever actualized with the desire of God. Fatalistic convictions were found over all religions, ages and sexes; anyway, individuals with less proper instruction had a dominance of superstitious just as fatalistic convictions, while individuals with progressively formal training offered expressions that demonstrated less superstitious convictions. Religion appeared to be a fundamental factor in molding convictions everything being equal. The statement underneath from a cop with a college degree outlines the quality of assessment communicated in all gatherings about the job of religion identifying with street crashes.

“...I have my solid confidence as a Muslim that life and demise is in the hands of God. I will get what is written in my destiny. I will get whatever is in my destiny like a mishap, infection and different issues throughout everyday life..." (P5U12).

“...The kids who expired in the accident would have passed on for some other explanation at any rate since death was their destiny and that was their day. This was inescapable and the driver's error just turns into the wellspring of that mishap. It was likewise the driver's predetermination that it was in his destiny to confront troubles of life along these lines..." (P4U11).

\section{Conclusion}

Since the objective of this study was to analyze the differential relationship of driving costs and advantages, selfesteem, and sensation seeking as a driver with proportions of crazy driving conduct and insights among late young people of age range 16-24 years (with median age as 21 years) with relation to gender differences. The study investigated the connection between these measures and two enthusiastic subjective plans of careless driving, foolish driving as worthy and attractive and crazy driving as negative and undermining, on the suspicion that these plans would prove an indistinguishable relationship with the measures from higher and lower paces of wild driving conduct, individually.

The study found that challenge and risk evaluation each made is a kind of commitment to foreseeing the readiness for risk driving, so that the higher the impression of hazardous driving as a test, the higher the eagerness to drive carelessly; the higher its observation as a risk, the lower the ability to go out on a limb out and about. Several studies suggested and pursues that endeavors to diminish reckless driving would do well to abstain from showing driving as a perplexing and requesting task, as this may urge adolescents to go out on a limb to exhibit their capacity to address the 
difficulty. As it is settled in the writing that youngsters will, in general, overlook the potential peril of unsafe driving and spotlight rather on the potential prizes, endeavors ought to be made to pressure the advantages that can get from cautious and capable conduct in the driver's seat. The Study likewise proposes that distracting exercises that require elevated levels of visual-manual assets are related with a moderately higher accident hazard than those activities that require largely cognitive resources. To start with restrictions to the present study, it ought to be noted that it depended on self-reports, which take into account the likelihood that the members' reactions didn't precisely mirror their conduct as a general rule. Therefore, it might be improper to endeavor to sum up the discoveries to different circumstances and driver gatherings. Also, there was no endeavor to control for factors that have generally been related to looking at forceful driving, for example, attribute outrage, characteristic animosity, past crash history, etc. The findings likewise affirmed the theory concerning the factor of subjective norms: the higher the view of risky driving as a social standard, the higher the readiness to take part in it. Projects planned for expanding wellbeing out and about would in this way, be encouraged to address this issue.

\section{Conflicts of Interest}

The authors declare no conflict of interest.

\section{References}

[1] Atubi, Augustus O., K. T. Gbadamosi, and N. A. Anichebe. "Global positioning, socioeconomic impact and management of road traffic accidents in Nigeria." Sustainable human development review 7, no. 1/4 (2016): 57-82.

[2] Wang, R., J. Gong, Y. Wang, H. Chen, S. Chen, and Q. Wang. "Relationship between gross domestic product and accident in China." Journal of Safety Studies 3, no. 1 (2017): 19-26.

[3] OECD/ECMT, "Young Drivers. The Road to Safety." European Conference of Ministers of Transport, and United Nations. Economic Commission for Europe. OECD Publishing, Paris, (2006).

[4] WHO, Global Status Report on Road Safety. 2018: Geneva. Available online: https://apps.who.int/iris/bitstream/handle/10665/277370/WHO-NMH-NVI-18.20-eng.pdf

[5] PBS, Traffic Accidents (Yearly). 2019: Islamabad, Pakistan. Available online: http://www.pbs.gov.pk/content/traffic-accidentsannual

[6] Lateef, Muhammad U. "Spatial Patterns Monitoring of Road Traffic Injuries in Karachi Metropolis." International Journal of Injury Control and Safety Promotion 18, no. 2 (June 2011): 97-105. doi:10.1080/17457300.2010.490588.

[7] Jooma, Rashid, and Masood Ali Shaikh. "Descriptive epidemiology of Karachi road traffic crash mortality in 2015." The Journal of the Pakistan Medical Association. 68, no. 5 (2018): 376.

[8] Peden, Margie, Richard Scurfield, David Sleet, Adnan A. Hyder, C. Mathers, Eva Jarawan, A. A. Hyder, D. Mohan, and E. Jarawan. World report on road traffic injury prevention. World Health Organization, (2004).

[9] Andrey, J., and Richard Olley. "Relationships between weather and road safety: past and future research directions." Climatological Bulletin 24, no. 3 (1990): 123-137.

[10] Ameratunga, Shanthi, Martha Hijar, and Robyn Norton. "Road-Traffic Injuries: Confronting Disparities to Address a GlobalHealth Problem.” The Lancet 367, no. 9521 (May 2006): 1533-1540. doi:10.1016/s0140-6736(06)68654-6.

[11] Damsere-Derry, James, Beth E. Ebel, Charles N. Mock, Francis Afukaar, and Peter Donkor. 'Pedestrians' Injury Patterns in Ghana.” Accident Analysis \& Prevention 42, no. 4 (July 2010): 1080-1088. doi:10.1016/j.aap.2009.12.016.

[12] Babcock, Michael W., and Philip G. Gayle. State variation in the determinants of motor vehicle fatalities. No. 1429-2016118658. 2009.

[13] Khan, Abdul Manan, and Ansa Tehreem. "Causes of road accidents in Pakistan." Journal of Asian Development Studies 1, no. 1 (2012): 22-29.

[14] Ahmed, Aizaza. "Road safety in Pakistan." National Road Safety Secretariat, Ministry of Communications Government of Pakistan Asian Development Bank, Islamabad 142 (2007).

[15] Vassallo, Suzanne, Diana Smart, Ann Sanson, Samantha Cockfield, Anne Harris, Allison McIntyre, and Warren Harrison. "Risky Driving Among Young Australian Drivers II: Co-Occurrence with Other Problem Behaviours." Accident Analysis \& Prevention 40, no. 1 (January 2008): 376-386. doi:10.1016/j.aap.2007.07.004.

[16] Elliott, Mark A., and Christopher J. Armitage. "Promoting drivers' compliance with speed limits: Testing an intervention based on the theory of planned behaviour." British journal of psychology 100, no. 1 (2009): 111-132. doi:10.1348/000712608X318626 
[17] Rhodes, Nancy, and Kelly Pivik. "Age and Gender Differences in Risky Driving: The Roles of Positive Affect and Risk Perception.” Accident Analysis \& Prevention 43, no. 3 (May 2011): 923-931. doi:10.1016/j.aap.2010.11.015.

[18] O'Brien, Sharon Rosemary. "The psychosocial factors influencing aggressive driving behaviour." PhD diss., Queensland University of Technology, (2011).

[19] Mesken, Jolieke, Marjan P. Hagenzieker, Talib Rothengatter, and Dick de Waard. "Frequency, Determinants, and Consequences of Different Drivers' Emotions: An on-the-Road Study Using Self-Reports, (observed) Behaviour, and Physiology." Transportation Research Part F: Traffic Psychology and Behaviour 10, no. 6 (November 2007): 458-475. doi:10.1016/j.trf.2007.05.001.

[20] Levelt, P., Field study of emotions in traffic: questionnaire study of features such as frequency, cause, and road safety effects. (2003).

[21] Berkowitz, Leonard. "McGraw-Hill series in social psychology. Aggression: Its causes, consequences, and control." McgrawHill Book Company (1993).

[22] Berkowitz, Leonard. "Frustration-Aggression Hypothesis: Examination and Reformulation.” Psychological Bulletin 106, no. 1 (1989): 59-73. doi:10.1037/0033-2909.106.1.59.

[23] Taubman - Ben-Ari, Orit. "The Effects of Positive Emotion Priming on Self-Reported Reckless Driving.” Accident Analysis \& Prevention 45 (March 2012): 718-725. doi:10.1016/j.aap.2011.09.039.

[24] Ben-Ari, Orit Taubman, Victor Florian, and Mario Mikulincer. "The impact of mortality salience on reckless driving: A test of terror management mechanisms." Journal of personality and social psychology 76, no. 1 (1999): 35.

[25] Eherenfreund-Hager, Ahinoam, and Orit Taubman - Ben-Ari. "The Effect of Affect Induction and Personal Variables on Young Drivers' Willingness to Drive Recklessly.” Transportation Research Part F: Traffic Psychology and Behaviour 41 (August 2016): 138-149. doi:10.1016/j.trf.2016.06.008.

[26] Zuckerman, Marvin. "The Psychophysiology of Sensation Seeking.” Journal of Personality 58, no. 1 (March 1990): 313-345. doi:10.1111/j.1467-6494.1990.tb00918.x.

[27] Jonah, Brian A., Rachel Thiessen, and Elaine Au-Yeung. "Sensation Seeking, Risky Driving and Behavioral Adaptation." Accident Analysis \& Prevention 33, no. 5 (September 2001): 679-684. doi:10.1016/s0001-4575(00)00085-3.

[28] McKenna, Frank P., and Mark S. Horswill. "Risk taking from the participant's perspective: The case of driving and accident risk." Health Psychology 25, no. 2 (2006): 163. doi:10.1037/0278-6133.25.2.163.

[29] Danaf, Mazen, Maya Abou-Zeid, and Isam Kaysi. "Modeling Anger and Aggressive Driving Behavior in a Dynamic Choicelatent Variable Model.” Accident Analysis \& Prevention 75 (February 2015): 105-118. doi:10.1016/j.aap.2014.11.012.

[30] Zhang, Tingru, and Alan H.S. Chan. "The Association Between Driving Anger and Driving Outcomes: A Meta-Analysis of Evidence from the Past Twenty Years." Accident Analysis \& Prevention 90 (May 2016): 50-62. doi:10.1016/j.aap.2016.02.009.

[31] Hennessy, Dwight. "Social, Personality, and Affective Constructs in Driving." Handbook of Traffic Psychology (2011): 149163. doi:10.1016/b978-0-12-381984-0.10012-8.

[32] Fernandes, Ralston, Julie Hatfield, and R.F. Soames Job. "A Systematic Investigation of the Differential Predictors for Speeding, Drink-Driving, Driving While Fatigued, and Not Wearing a Seat Belt, Among Young Drivers." Transportation Research Part F: Traffic Psychology and Behaviour 13, no. 3 (May 2010): 179-196. doi:10.1016/j.trf.2010.04.007.

[33] Fernandes, Ralston, R.F. Soames Job, and Julie Hatfield. "A Challenge to the Assumed Generalizability of Prediction and Countermeasure for Risky Driving: Different Factors Predict Different Risky Driving Behaviors.” Journal of Safety Research 38, no. 1 (January 2007): 59-70. doi:10.1016/j.jsr.2006.09.003.

[34] Iversen, Hilde. "Risk-Taking Attitudes and Risky Driving Behaviour.” Transportation Research Part F: Traffic Psychology and Behaviour 7, no. 3 (May 2004): 135-150. doi:10.1016/j.trf.2003.11.003.

[35] Elander, James, Robert West, and Davina French. "Behavioral correlates of individual differences in road-traffic crash risk: An examination of methods and findings." Psychological bulletin 113, no. 2 (1993): 279.

[36] Rundmo, TorbjØrn. “Associations Between Affect and Risk Perception.” Journal of Risk Research 5, no. 2 (April 2002): 119135. doi:10.1080/136698702753499597.

[37] Slovic, Paul, Melissa L. Finucane, Ellen Peters, and Donald G. MacGregor. "Risk as Analysis and Risk as Feelings: Some Thoughts About Affect, Reason, Risk, and Rationality.” Risk Analysis 24, no. 2 (April 2004): 311-322. doi:10.1111/j.02724332.2004.00433.x.

[38] Mesken, J. "Determinants and consequences of drivers' emotions. Proefschrift Rijksuniversiteit Groningen RUG, Groningen." (2006). 
[39] Isen, Alice M. "Some perspectives on positive affect and self-regulation." Psychological Inquiry 11, no. 3 (2000): 184-187.

[40] Fiedler, Klaus, and Herbert Bless. "The Formation of Beliefs at the Interface of Affective and Cognitive Processes." Emotions and Beliefs (October 12, 2000): 144-170. doi:10.1017/cbo9780511659904.006.

[41] Dalgleish, Tim, and Mick Power. Cognition and emotion: From order to disorder. New York/London: Psychology press, (2015).

[42] Cavanaugh, Lisa A., James R. Bettman, Mary Frances Luce, and John W. Payne. “Appraising the Appraisal-Tendency Framework.” Journal of Consumer Psychology 17, no. 3 (July 2007): 169-173. doi:10.1016/s1057-7408(07)70024-4.

[43] Hu, Tian-Yi, Xiaofei Xie, and Jie Li. "Negative or Positive? The Effect of Emotion and Mood on Risky Driving." Transportation Research Part F: Traffic Psychology and Behaviour 16 (January 2013): 29-40. doi:10.1016/j.trf.2012.08.009.

[44] Murray, Christopher JL, Alan D. Lopez, and World Health Organization. The global burden of disease: a comprehensive assessment of mortality and disability from diseases, injuries, and risk factors in 1990 and projected to 2020: summary. World Health Organization, (1996).

[45] Pakistan, S.B.o., The Pakistan infrastructure report. 2009, State Bank of Pakistan: Islamabad, Pakistan. Available online: www.sbp.org.pk/publications/index2.asp

[46] Hussain, Tabish, L. Shu, T. Sosorburan, A. Seid Adji, Ali Hassan Khan, and A. F. Raja. "Road traffic accidents: an observational and analytical study exploring the hidden truths in Pakistan and South East Asian countries." Healthline 2, no. 1 (2011): 52-57.

[47] Khan, Adeel Ahmed, and Zafar Fatmi. "Strategies for prevention of road traffic injuries (RTIs) in Pakistan: situational analysis." Journal of College Physicians Surgeons Pakakistan 24, no. 5 (2014): 356.

[48] Mphela, Thuso. "The Impact of Traffic Law Enforcement on Road Accident Fatalities in Botswana.” Journal of Transport and Supply Chain Management 5, no. 1 (November 26, 2011): 264-277. doi:10.4102/jtscm.v5i1.77.

[49] Afukaar, Francis K., Phyllis Antwi, and Samuel Ofosu-Amaah. "Pattern of Road Traffic Injuries in Ghana: Implications for Control.” Injury Control and Safety Promotion 10, no. 1-2 (April 2003): 69-76. doi:10.1076/icsp.10.1.69.14107.

[50] Cao, Xinyu, Susan L. Handy, and Patricia L. Mokhtarian. "The Influences of the Built Environment and Residential SelfSelection on Pedestrian Behavior: Evidence from Austin, TX.” Transportation 33, no. 1 (January 2006): 1-20. doi:10.1007/s11116-005-7027-2.

[51] Summala, Heikki. "Risk Control Is Not Risk Adjustment: The Zero-Risk Theory of Driver Behaviour and Its Implications." Ergonomics 31, no. 4 (April 1988): 491-506. doi:10.1080/00140138808966694.

[52] Vaa, Truls. "Modelling Driver Behaviour on Basis of Emotions and Feelings: Intelligent Transport Systems and Behavioural Adaptations." Modelling Driver Behaviour in Automotive Environments (2007): 208-232. doi:10.1007/978-1-84628-618-6_12.

[53] Wilde, Gerald J. S. “The Theory of Risk Homeostasis: Implications for Safety and Health.” Risk Analysis 2, no. 4 (December 1982): 209-225. doi:10.1111/j.1539-6924.1982.tb01384.x.

[54] Summala, Heikki. "Towards Understanding Motivational and Emotional Factors in Driver Behaviour: Comfort Through Satisficing.” Modelling Driver Behaviour in Automotive Environments (2007): 189-207. doi:10.1007/978-1-84628-618-6_11.

[55] Fuller, Ray. "Towards a General Theory of Driver Behaviour." Accident Analysis \& Prevention 37, no. 3 (May 2005): 461472. doi:10.1016/j.aap.2004.11.003.

[56] Fuller, Ray. "Driver Control Theory.” Handbook of Traffic Psychology (2011): 13-26. doi:10.1016/b978-0-12-3819840.10002-5.

[57] Fuller, R., H. Bates, M. Gormley, B. Hannigan, S. Stradling, P. Broughton, N. Kinnear, and C. O'dolan. "The conditions for inappropriate high speed: A review of the research literature from 1995 to 2006." Report under Contract Number PPRO (2008).

[58] Fuller, R., C. McHugh, and S. Pender. “Task Difficulty and Risk in the Determination of Driver Behaviour.” European Review of Applied Psychology 58, no. 1 (March 2008): 13-21. doi:10.1016/j.erap.2005.07.004.

[59] Alm, Håkan, and Lena Nilsson. "The Effects of a Mobile Telephone Task on Driver Behaviour in a Car Following Situation." Accident Analysis \& Prevention 27, no. 5 (October 1995): 707-715. doi:10.1016/0001-4575(95)00026-v.

[60] Chisholm, S.L., J.K. Caird, and J. Lockhart. “The Effects of Practice with MP3 Players on Driving Performance.” Accident Analysis \& Prevention 40, no. 2 (March 2008): 704-713. doi:10.1016/j.aap.2007.09.014.

[61] Patten, Christopher J.D, Albert Kircher, Joakim Östlund, and Lena Nilsson. "Using Mobile Telephones: Cognitive Workload and Attention Resource Allocation." Accident Analysis \& Prevention 36, no. 3 (May 2004): 341-350. doi:10.1016/s00014575(03)00014-9. 
[62] Rudin-Brown, Christina M., and Heather A. Parker. "Behavioural Adaptation to Adaptive Cruise Control (ACC): Implications for Preventive Strategies.” Transportation Research Part F: Traffic Psychology and Behaviour 7, no. 2 (March 2004): 59-76. doi:10.1016/j.trf.2004.02.001.

[63] Summala, Heikki. "Behavioural Adaptation and Drivers' Task Control." Human factors for highway engineers (2002).

[64] Ulleberg, Pål, and Torbjørn Rundmo. "Personality, Attitudes and Risk Perception as Predictors of Risky Driving Behaviour Among Young Drivers.” Safety Science 41, no. 5 (June 2003): 427-443. doi:10.1016/s0925-7535(01)00077-7.

[65] Byrnes, J. P. "The development of judgement and decision making in children and adolescents." In The development of selfregulated decision making (2005): 5-38.

[66] Greene, Kathryn, Marina Krcmar, Lynda H Walters, Donald L Rubin, Jerold, and L Hale. "Targeting Adolescent Risk-Taking Behaviors: The Contributions of Egocentrism and Sensation-Seeking." Journal of Adolescence 23, no. 4 (August 2000): 439461. doi:10.1006/jado.2000.0330.

[67] Turner, Cathy, and Rod McClure. "Quantifying the Role of Risk-Taking Behaviour in Causation of Serious Road CrashRelated Injury.” Accident Analysis \& Prevention 36, no. 3 (May 2004): 383-389. doi:10.1016/s0001-4575(03)00031-9.

[68] Mercer, G. William, And Wayne K. Jeffery. "Patterns of Convictions and Traffic Accident Involvement." Criminal Behaviour and Mental Health 5, no. 4 (November 1995): 463-478. doi:10.1002/cbm.1995.5.4.463.

[69] Mittal, Vikas, and William T Ross. "The Impact of Positive and Negative Affect and Issue Framing on Issue Interpretation and Risk Taking." Organizational Behavior and Human Decision Processes 76, no. 3 (December 1998): 298-324. doi:10.1006/obhd.1998.2808.

[70] Boyer, T. “The Development of Risk-Taking: A Multi-Perspective Review.” Developmental Review 26, no. 3 (September 2006): 291-345. doi:10.1016/j.dr.2006.05.002.

[71] Shinar, David, and Richard Compton. "Aggressive Driving: An Observational Study of Driver, Vehicle, and Situational Variables." Accident Analysis \& Prevention 36, no. 3 (May 2004): 429-437. doi:10.1016/s0001-4575(03)00037-x.

[72] Simons-Morton, Bruce, Neil Lerner, and Jeremiah Singer. "The Observed Effects of Teenage Passengers on the Risky Driving Behavior of Teenage Drivers." Accident Analysis \& Prevention 37, no. 6 (November 2005): 973-982. doi:10.1016/j.aap.2005.04.014.

[73] Khattak, Asad J., and André De Palma. "The Impact of Adverse Weather Conditions on the Propensity to Change Travel Decisions: A Survey of Brussels Commuters.” Transportation Research Part A: Policy and Practice 31, no. 3 (May 1997): 181-203. doi:10.1016/s0965-8564(96)00025-0.

[74] De Palma, André, and Denis Rochat. "Understanding individual travel decisions: results from a commuters survey in Geneva." Transportation 26, no. 3 (1999): 263-281. doi:10.1023/A:1005121605832.

[75] Winters, Meghan, Melissa C. Friesen, Mieke Koehoorn, and Kay Teschke. "Utilitarian Bicycling." American Journal of Preventive Medicine 32, no. 1 (January 2007): 52-58. doi:10.1016/j.amepre.2006.08.027.

[76] Saneinejad, S., C. Kennedy, and M. J. Roorda. "Assessing the impact of weather and climate on commuter trip behaviour in Toronto." In Panamerican Conference on Traffic Control and Transportation Engineering. (2010).

[77] Bergel-Hayat, Ruth, Mohammed Debbarh, Constantinos Antoniou, and George Yannis. "Explaining the Road Accident Risk: Weather Effects.” Accident Analysis \& Prevention 60 (November 2013): 456-465. doi:10.1016/j.aap.2013.03.006.

[78] Söderlund, Neil, and Anthony B. Zwi. "Traffic-related mortality in industrialized and less developed countries." Bulletin of the World Health Organization 73, no. 2 (1995): 175.

[79] Ghaffar, A., et al., Road crashes: a modern plague on South Asia's poor. Journal of the College of Physicians and Surgeons-Pakistan: JCPSP, 2004. 14(12): p. 739-741.

[80] Nantulya, Vinand M., and Michael R. Reich. "Equity Dimensions of Road Traffic Injuries in Low- and Middle-Income Countries." Injury Control and Safety Promotion 10, no. 1-2 (April 2003): 13-20. doi:10.1076/icsp.10.1.13.14116.

[81] Suriyawongpaisal, Paibul, and Somchai Kanchanasut. "Road Traffic Injuries in Thailand: Trends, Selected Underlying Determinants and Status of Intervention.” Injury Control and Safety Promotion 10, no. 1-2 (April 2003): 95-104. doi:10.1076/icsp.10.1.95.14110.

[82] Yang, Bong-Min, and Jinhyun Kim. "Road Traffic Accidents and Policy Interventions in Korea.” Injury Control and Safety Promotion 10, no. 1-2 (April 2003): 89-94. doi:10.1076/icsp.10.1.89.14120.

[83] Collier, J., Automotive safety education London., Macmillan Publishers, (1983).

[84] Kim, Jiwon, Hani S. Mahmassani, Roemer Alfelor, Ying Chen, Tian Hou, Lan Jiang, Meead Saberi, Ömer Verbas, and Ali Zockaie. "Implementation and Evaluation of Weather-Responsive Traffic Management Strategies." Transportation Research Record: Journal of the Transportation Research Board 2396, no. 1 (January 2013): 93-106. doi:10.3141/2396-11. 
[85] Theofilatos, Athanasios, and George Yannis. "A Review of the Effect of Traffic and Weather Characteristics on Road Safety." Accident Analysis \& Prevention 72 (November 2014): 244-256. doi:10.1016/j.aap.2014.06.017.

[86] Usman, Taimur, Liping Fu, and Luis F. Miranda-Moreno. "A Disaggregate Model for Quantifying the Safety Effects of Winter Road Maintenance Activities at an Operational Level.” Accident Analysis \& Prevention 48 (September 2012): 368378. doi:10.1016/j.aap.2012.02.005.

[87] Andrey, Jean, and Sam Yagar. "A Temporal Analysis of Rain-Related Crash Risk.” Accident Analysis \& Prevention 25, no. 4 (August 1993): 465-472. doi:10.1016/0001-4575(93)90076-9.

[88] Soltani, Nemat, Mahmoud Saffarzadeh, and Ali Naderan. "Multi-Level Crash Prediction Models Considering Influence of Adjacent Zonal Attributes.” Civil Engineering Journal 5, no. 3 (March 18, 2019): 649. doi:10.28991/cej-2019-03091276.

[89] Laaidi, K., and M. Laaidi. "Météorologie et sécurité routière." La Presse thermale et climatique 134, no. 4 (1997): 269 -274.

[90] Hancock, P. A., and Ioannis Vasmatzidis. "Human Occupational and Performance Limits Under Stress: The Thermal Environment as a Prototypical Example.” Ergonomics 41, no. 8 (August 1998): 1169-1191. doi:10.1080/001401398186469.

[91] Hancock, P. A., and I. Vasmatzidis. "Effects of Heat Stress on Cognitive Performance: The Current State of Knowledge." International Journal of Hyperthermia 19, no. 3 (January 2003): 355-372. doi:10.1080/0265673021000054630.

[92] Brijs, Tom, Dimitris Karlis, and Geert Wets. "Studying the Effect of Weather Conditions on Daily Crash Counts Using a Discrete Time-Series Model." Accident Analysis \& Prevention 40, no. 3 (May 2008): 1180-1190. doi:10.1016/j.aap.2008.01.001.

[93] Hermans, Elke, Geert Wets, and Filip Van den Bossche. "Frequency and severity of Belgian road traffic accidents studied by state-space methods." Journal of Transportation and Statistics 9, no. 1 (2006): 63.

[94] Vlassenroot, Sven, Steven Broekx, Johan De Mol, Luc Int Panis, Tom Brijs, and Geert Wets. "Driving with Intelligent Speed Adaptation: Final Results of the Belgian ISA-Trial." Transportation Research Part A: Policy and Practice 41, no. 3 (March 2007): 267-279. doi:10.1016/j.tra.2006.05.009.

[95] Bergel-Hayat, Ruth. "Time-Series Models of Aggregate Road Risk and Their Applications to European Countries.” Transport Reviews 32, no. 5 (September 2012): 653-670. doi:10.1080/01441647.2012.695407.

[96] Malyshkina, Nataliya V., Fred L. Mannering, and Andrew P. Tarko. "Markov Switching Negative Binomial Models: An Application to Vehicle Accident Frequencies." Accident Analysis \& Prevention 41, no. 2 (March 2009): $217-226$. doi:10.1016/j.aap.2008.11.001.

[97] Edwards, Julia B. “The Temporal Distribution of Road Accidents in Adverse Weather.” Meteorological Applications 6, no. 1 (March 1999): 59-68. doi:10.1017/s1350482799001139.

[98] Qiu, Lin, and Wilfrid A. Nixon. "Effects of Adverse Weather on Traffic Crashes." Transportation Research Record: Journal of the Transportation Research Board 2055, no. 1 (January 2008): 139-146. doi:10.3141/2055-16.

[99] Fridstrøm, Lasse, Jan Ifver, Siv Ingebrigtsen, Risto Kulmala, and Lars Krogsgård Thomsen. "Measuring the Contribution of Randomness, Exposure, Weather, and Daylight to the Variation in Road Accident Counts." Accident Analysis \& Prevention 27, no. 1 (February 1995): 1-20. doi:10.1016/0001-4575(94)e0023-e.

[100] Andrey, Jean, Brian Mills, Mike Leahy, and Jeff Suggett. "Weather as a chronic hazard for road transportation in Canadian cities." Natural Hazards 28, no. 2-3 (2003): 319-343. doi:10.1023/A:1022934225431.

[101] Hambly, Derrick, Jean Andrey, Brian Mills, and Chris Fletcher. "Projected Implications of Climate Change for Road Safety in Greater Vancouver, Canada.” Climatic Change 116, no. 3-4 (May 23, 2012): 613-629. doi:10.1007/s10584-012-0499-0.

[102] Ellinghaus, D., ed. Wetter und Autofahren: Eine Untersuchung über den Einfluß des Wetters auf das Unfallgeschehen und die Verkehrssicherheit. IFAPLAN, (1984). Available online: https://library.swov.nl/action/front/cardweb?id=37717

[103] Fokkema, H. J. "Weersgesteldheid en verkeersveiligheid." Traffic Test in opdracht van Directie Verkeersveiligheid van het Ministerie van Verkeer en Waterstaat, Veenendaal (1987). Available online: https://www.swov.nl/sites/default/files/publicaties/rapport/r-97-03.pdf

[104] Andrey, Jean. "Long-Term Trends in Weather-Related Crash Risks." Journal of Transport Geography 18, no. 2 (March 2010): 247-258. doi:10.1016/j.jtrangeo.2009.05.002.

[105] IPCC, The physical science basis. Contribution of working group I to the fourth assessment report of the intergovernmental panel on climate change. Manning, M., Chen, Z., Marquis, M., Averyt, KB, Tignor, M., and Miller, HL, Cambridge University Press, Cambridge, UK and New York, NY, USA, 2007. 996: p. 2007.

[106] Eisenberg, Daniel. "The Mixed Effects of Precipitation on Traffic Crashes." Accident Analysis \& Prevention 36, no. 4 (July 2004): 637-647. doi:10.1016/s0001-4575(03)00085-x. 
[107] Charabi, Yassine, Sabah Abdul-Wahab, Ghazi Al-Rawas, Malik Al-Wardy, and Sulaiman Fadlallah. "Investigating the Impact of Monsoon Season on the Dispersion of Pollutants Emitted from Vehicles: A Case Study of Salalah City, Sultanate of Oman." Transportation Research Part D: Transport and Environment 59 (March 2018): 108-120. doi:10.1016/j.trd.2017.12.019.

[108] Abdel-Aty, M.A., and R. Pemmanaboina. "Calibrating a Real-Time Traffic Crash-Prediction Model Using Archived Weather and ITS Traffic Data." IEEE Transactions on Intelligent Transportation Systems 7, no. 2 (June 2006): 167-174. doi:10.1109/tits.2006.874710.

[109] Miller, D., G. Benedek, and C. Thomas, Intraocular light scattering. American Journal of Optometry and Archives of American Academy of Optometry, (1973). 50(12).

[110] Van Den Berg, T. J. T. P. “On the Relation between Glare and Straylight.” Documenta Ophthalmologica 78, no. 3-4 (September 1991): 177-181. doi:10.1007/bf00165678.

[111] Wolbarsht, Myron L. "Tests for glare sensitivity and peripheral vision in driver applicants." Journal of safety research (1977).

[112] Babizhayev, Mark A. "Glare Disability and Driving Safety." Ophthalmic Research 35, no. 1 (2003): 19-25. doi:10.1159/000068199.

[113] Zhang, Qian, Zuhua Jiang, Dongpeng Zheng, Yifan Wang, and Dong Man. "An Application of the Driver Behavior Questionnaire to Chinese Carless Young Drivers.” Traffic Injury Prevention 14, no. 8 (November 17, 2013): 867-873. doi:10.1080/15389588.2013.775432.

[114] Regan, D., D. E. Giaschi, and B. B. Fresco. "Measurement of Glare Sensitivity in Cataract Patients Using Low-Contrast Letter Charts." Ophthalmic and Physiological Optics 13, no. 2 (April 1993): 115-123. doi:10.1111/j.14751313.1993.tb00439.x.

[115] NHTSA "A compilation of motor vehicle crash data from the fatality analysis reporting system and the general estimates system." National Highway Traffic Safety Administration. DOT HS 809 (2003): 775.

[116] Hagita, Kenji, and Kenji Mori. "Analysis of the influence of sun glare on traffic accidents in Japan." Journal of the Eastern Asia Society for Transportation Studies 9 (2011): 1775-1785. doi:10.11175/easts.9.1775.

[117] Hagita, Kenji, and Kenji Mori. “An Analysis of Traffic Accident Influenced By Sun Glare.” Journal of Japan Society of Civil Engineers, Ser. D3 (Infrastructure Planning and Management) 67, no. 5 (2011): 1055-1062. doi:10.2208/jscejipm.67.67_i_1055.

[118] Hagita, K., and K. Mori. "Analysis of the influence of sun glare on pedestrian accidents." In 31st Japan Society of Traffic Engineers Annual Meeting. (2011).

[119] Hagita, Kenji, and Kenji Mori. "Analysis by vehicle types of traffic accident influenced by sun glare." Transactions of Society of Automotive Engineers of Japan 43, no. 3 (2012): 743-748. doi:10.11351/jsaeronbun.43.743.

[120] Mitra, Sudeshna. "Investigating impact of sun glare on transportation safety.” No. 08-2184. (2008).

[121] Jurado-Piña, Rafael, and José M. Pardillo Mayora. "Methodology to Predict Driver Vision Impairment Situations Caused by Sun Glare.” Transportation Research Record: Journal of the Transportation Research Board 2120, no. 1 (January 2009): 1217. doi:10.3141/2120-02.

[122] Jurado-Piña, R., J. M. Pardillo-Mayora, and R. Jiménez. "Methodology to Analyze Sun Glare Related Safety Problems at Highway Tunnel Exits.” Journal of Transportation Engineering 136, no. 6 (June 2010): 545-553. doi:10.1061/(asce)te.19435436.0000113.

[123] Daniel, Janice R., and Steven I. Chien. "Impact of adverse weather on freeway speeds and flows.” No. 09-2837. (2009).

[124] Wei, Ming, Bo Sun, Han Wang, and Zhihuo Xu. "A Multi-Attribute Decision-Making Model for the Evaluation of Uncertainties in Traffic Pollution Control Planning." Environmental Science and Pollution Research 26, no. 18 (November 4, 2017): 17911-17917. doi:10.1007/s11356-017-0631-9.

[125] Nie, Jing, Jan Beyea, Matthew R. Bonner, Daikwon Han, John E. Vena, Peter Rogerson, Dominica Vito, et al. "Exposure to Traffic Emissions Throughout Life and Risk of Breast Cancer: The Western New York Exposures and Breast Cancer (WEB) Study." Cancer Causes \& Control 18, no. 9 (July 14, 2007): 947-955. doi:10.1007/s10552-007-9036-2.

[126] Asif, Zunaira, and Zhi Chen. "Environmental Management in North American Mining Sector." Environmental Science and Pollution Research 23, no. 1 (November 3, 2015): 167-179. doi:10.1007/s11356-015-5651-8.

[127] Brown, Thomas C., George L. Peterson, R. Marc Brodersen, Valerie Ford, and Paul A. Bell. "The Judged Seriousness of an Environmental Loss Is a Matter of What Caused It.” Journal of Environmental Psychology 25, no. 1 (March 2005): 13-21. doi:10.1016/j.jenvp.2004.12.005. 
[128] Li, Yang, Hua Ping, Zhi-Hong Ma, and Li-Gang Pan. "Statistical Analysis of Sudden Chemical Leakage Accidents Reported in China Between 2006 and 2011.” Environmental Science and Pollution Research 21, no. 8 (January 10, 2014): 5547-5553. doi:10.1007/s11356-013-2279-4.

[129] Hooyberghs, J, C Mensink, G Dumont, F Fierens, and O Brasseur. "A Neural Network Forecast for Daily Average PM Concentrations in Belgium.” Atmospheric Environment 39, no. 18 (June 2005): 3279-3289. doi:10.1016/j.atmosenv.2005.01.050.

[130] Lonati, G., M. Giugliano, and S. Cernuschi. "The Role of Traffic Emissions from Weekends' and Weekdays' Fine PM Data in Milan.” Atmospheric Environment 40, no. 31 (October 2006): 5998-6011. doi:10.1016/j.atmosenv.2005.12.033.

[131] Nava, S., F. Lucarelli, F. Amato, S. Becagli, G. Calzolai, M. Chiari, M. Giannoni, R. Traversi, and R. Udisti. "Biomass Burning Contributions Estimated by Synergistic Coupling of Daily and Hourly Aerosol Composition Records." Science of the Total Environment 511 (April 2015): 11-20. doi:10.1016/j.scitotenv.2014.11.034.

[132] Unal, Yurdanur S., Hüseyin Toros, Ali Deniz, and Selahattin Incecik. "Influence of Meteorological Factors and Emission Sources on Spatial and Temporal Variations of PM10 Concentrations in Istanbul Metropolitan Area." Atmospheric Environment 45, no. 31 (October 2011): 5504-5513. doi:10.1016/j.atmosenv.2011.06.039.

[133] Van der Wal, J.T, and L.H.J.M Janssen. "Analysis of Spatial and Temporal Variations of PM 10 Concentrations in the Netherlands Using Kalman Filtering.” Atmospheric Environment 34, no. 22 (January 2000): 3675-3687. doi:10.1016/s13522310(00)00085-6.

[134] Auffhammer, Maximilian, Maoyong Fan, and Hendrik Wolff. "Choking behind the wheel: the effect of air pollution on vehicle accidents." University of California, Berkeley and NBER Ball State University (2017).

[135] Bahadorimonfared, Ayad, Hamid Soori, Yadollah Mehrabi, Ali Delpisheh, Alireza Esmaili, Masoud Salehi, and Mahmood Bakhtiyari. "Trends of fatal road traffic injuries in Iran (2004-2011)." PloS one 8, no. 5 (2013): e65198. doi:10.1371/journal.pone.0065198.t001

[136] Shams, Mohsen, Davoud Shojaeizadeh, Reza Majdzadeh, Arash Rashidian, and Ali Montazeri. "Taxi Drivers' Views on Risky Driving Behavior in Tehran: A Qualitative Study Using a Social Marketing Approach.” Accident Analysis \& Prevention 43, no. 3 (May 2011): 646-651. doi:10.1016/j.aap.2010.10.007.

[137] Curry, Allison E., Jessica H. Mirman, Michael J. Kallan, Flaura K. Winston, and Dennis R. Durbin. "Peer Passengers: How Do They Affect Teen Crashes?" Journal of Adolescent Health 50, no. 6 (June 2012): 588-594. doi:10.1016/j.jadohealth.2011.10.016.

[138] McKnight, A.James, and A.Scott McKnight. "Young Novice Drivers: Careless or Clueless?" Accident Analysis \& Prevention 35, no. 6 (November 2003): 921-925. doi:10.1016/s0001-4575(02)00100-8.

[139] Shepherd, Jennifer L., David J. Lane, Ryan L. Tapscott, and Douglas A. Gentile. "Susceptible to Social Influence: Risky 'Driving' in Response to Peer Pressure1.” Journal of Applied Social Psychology 41, no. 4 (April 2011): $773-797$. doi:10.1111/j.1559-1816.2011.00735.x.

[140] Toxopeus, Ryan, Robert Ramkhalawansingh, and Lana Trick. "The Influence of Passenger-Driver Interaction on Young Drivers." Proceedings of the 6th International Driving Symposium on Human Factors in Driver Assessment, Training, and Vehicle Design : Driving Assessment (2011). doi:10.17077/drivingassessment.1379.

[141] Williams, A F. "Seatbelt Use by High School Students." Injury Prevention 9, no. 1 (March 1, 2003 ): $25-28$. doi:10.1136/ip.9.1.25.

[142] White, Cale B., and Jeff K. Caird. "The Blind Date: The Effects of Change Blindness, Passenger Conversation and Gender on Looked-but-Failed-to-See (LBFTS) Errors.” Accident Analysis \& Prevention 42, no. 6 (November 2010): 1822-1830. doi:10.1016/j.aap.2010.05.003.

[143] Gugerty, Leo, Mick Rakauskas, and Johnell Brooks. "Effects of Remote and in-Person Verbal Interactions on Verbalization Rates and Attention to Dynamic Spatial Scenes.” Accident Analysis \& Prevention 36, no. 6 (November 2004): 1029-1043. doi:10.1016/j.aap.2003.12.002.

[144] Rivardo, Mark G., Maria L. Pacella, and Brandi A. Klein. "Simulated Driving Performance is worse with a Passenger than a Simulated Cellular Telephone Converser." North American Journal of Psychology 10, no. 2 (2008).

[145] Chen, Li-Hui, Susan P. Baker, Elisa R. Braver, and Guohua Li. "Carrying passengers as a risk factor for crashes fatal to 16and 17-year-old drivers." Jama 283, no. 12 (2000): 1578-1582.

[146] Simons-Morton, Bruce G., Marie Claude Ouimet, Zhiwei Zhang, Sheila E. Klauer, Suzanne E. Lee, Jing Wang, Rusan Chen, Paul Albert, and Thomas A. Dingus. "The Effect of Passengers and Risk-Taking Friends on Risky Driving and Crashes/Near Crashes among Novice Teenagers." Journal of Adolescent Health 49, no. 6 (December 2011): 587-593. doi:10.1016/j.jadohealth.2011.02.009. 
[147] Drews, Frank A., Monisha Pasupathi, and David L. Strayer. "Passenger and Cell Phone Conversations in Simulated Driving." Journal of Experimental Psychology: Applied 14, no. 4 (2008): 392-400. doi:10.1037/a0013119.

[148] Jenkins, Jennifer M., and Keith Oatley. "Emotional Episodes and Emotionality through the Life Span." Handbook of Emotion, Adult Development, and Aging (1996): 421-441. doi:10.1016/b978-012464995-8/50024-8.

[149] Dejong, William, and Charles K. Atkin. “A Review of National Television PSA Campaigns for Preventing Alcohol-Impaired Driving, 1987-1992.” Journal of Public Health Policy 16, no. 1 (1995): 59-80. doi:10.2307/3342977.

[150] Tay, Richard. "The Effectiveness of Enforcement and Publicity Campaigns on Serious Crashes Involving Young Male Drivers: Are Drink Driving and Speeding Similar?” Accident Analysis \& Prevention 37, no. 5 (September 2005): $922-929$. doi:10.1016/j.aap.2005.04.010.

[151] Whittam, Kimberly P., William O. Dwyer, Patricia W. Simpson, and Frank C. Leeming. "Effectiveness of a Media Campaign to Reduce." Journal of Applied Social Psychology 36, no. 3 (March 30, 2006): 614-628. doi:10.1111/j.00219029.2006.00021.x.

[152] DeSteno, David, Richard E. Petty, Derek D. Rucker, Duane T. Wegener, and Julia Braverman. "Discrete Emotions and Persuasion: The Role of Emotion-Induced Expectancies.” Journal of Personality and Social Psychology 86, no. 1 (January 2004): 43-56. doi:10.1037/0022-3514.86.1.43.

[153] Maheswaran, Durairaj, and Cathy Yi Chen. "Nation Equity: Incidental Emotions in Country-of-Origin Effects." Journal of Consumer Research 33, no. 3 (December 2006): 370-376. doi:10.1086/508521.

[154] Rhodes, Nancy, Kelly Pivik, and Marnie Sutton. "Risky Driving Among Young Male Drivers: The Effects of Mood and Passengers." Transportation Research Part F: Traffic Psychology and Behaviour 28 (January 2015): 65-76. doi:10.1016/j.trf.2014.11.005.

[155] Zuckerman, M., "Behavioral expressions and biosocial bases of sensation seeking." Cambridge University Press. (1994).

[156] Eysenck, Hans J. "A biometrical-genetical analysis of impulsive and sensation seeking behavior." Biological bases of sensation seeking, impulsivity, and anxiety (1983): 1-27.

[157] Zuckerman, Marvin, Elizabeth A. Kolin, Leah Price, and Ina Zoob. "Development of a Sensation-Seeking Scale.” Journal of Consulting Psychology 28, no. 6 (1964): 477-482. doi:10.1037/h0040995.

[158] Arnett, Jeffrey. "Drunk Driving, Sensation Seeking, and Egocentrism among Adolescents." Personality and Individual Differences 11, no. 6 (January 1990): 541-546. doi:10.1016/0191-8869(90)90035-p.

[159] Heino, Adriaan, H. H. Van der Molen, and Gerrit Johan Steven Wilde. Risk-homeostatic processes in car-following behaviour: Individual differences in car-following and perceived risk. No. VK 92-02. (1992).

[160] Horvath, Paula, and Marvin Zuckerman. "Sensation Seeking, Risk Appraisal, and Risky Behavior." Personality and Individual Differences 14, no. 1 (January 1993): 41-52. doi:10.1016/0191-8869(93)90173-z.

[161] Yu, Jiang, and William R. Williford. “Alcohol and Risk/Sensation Seeking:” Journal of Addictive Diseases 12, no. 1 (January 5, 1993): 79-96. doi:10.1300/j069v12n01_07.

[162] Fuller, Ray. “A Conceptualization of Driving Behaviour as Threat Avoidance.” Ergonomics 27, no. 11 (November 1984): 1139-1155. doi:10.1080/00140138408963596.

[163] Benjamin, Jonathan, Lin Li, Chavis Patterson, Benjamin D. Greenberg, Dennis L. Murphy, and Dean H. Hamer. "Population and Familial Association Between the D4 Dopamine Receptor Gene and Measures of Novelty Seeking." Nature Genetics 12, no. 1 (January 1996): 81-84. doi:10.1038/ng0196-81.

[164] Ebstein, Richard P., Olga Novick, Roberto Umansky, Beatrice Priel, Yamima Osher, Darren Blaine, Estelle R. Bennett, Lubov Nemanov, Miri Katz, and Robert H. Belmaker. "Dopamine D4 Receptor (D4DR) Exon III Polymorphism Associated with the Human Personality Trait of Novelty Seeking." Nature Genetics 12, no. 1 (January 1996): 78-80. doi:10.1038/ng0196-78.

[165] Taubman - Ben-Ari, O. "Motivational Sources of Driving and Their Associations with Reckless Driving Cognitions and Behavior.” European Review of Applied Psychology 58, no. 1 (March 2008): 51-64. doi:10.1016/j.erap.2005.08.002.

[166] Taubman - Ben-Ari, Orit. "The Effect of Reminders of Death on Reckless Driving." Current Directions in Psychological Science 9, no. 6 (December 2000): 196-199. doi:10.1111/1467-8721.00093.

[167] Cooper, M. Lynne, Cheryl M. Shapiro, and Anne M. Powers. "Motivations for Sex and Risky Sexual Behavior among Adolescents and Young Adults: A Functional Perspective.” Journal of Personality and Social Psychology 75, no. 6 (1998): 1528-1558. doi:10.1037/0022-3514.75.6.1528.

[168] Deci, Edward L., and Richard M. Ryan. "Self-Determination Theory." Handbook of Theories of Social Psychology: Volume 1 (2012): 416-437. doi:10.4135/9781446249215.n21. 
[169] Taubman-Ben-Ari, O. R. I. T. "Risk taking in adolescence." Handbook of experimental existential psychology (2004): 106.

[170] Markus, H, and E Wurf. “The Dynamic Self-Concept: A Social Psychological Perspective.” Annual Review of Psychology 38, no. 1 (January 1987): 299-337. doi:10.1146/annurev.ps.38.020187.001503.

[171] Bandura, Albert. "Theoretical perspectives." Self-efficacy: The exercise of control (1997): 1-35.

[172] McAuley, Edward, and Lynn Jacobson. "Self-Efficacy and Exercise Participation in Sedentary Adult Females.” American Journal of Health Promotion 5, no. 3 (January 1991): 185-207. doi:10.4278/0890-1171-5.3.185. 